\title{
Nahrung und Freßverhalten bei Sedimentfressern dargestellt am Beispiel von Sipunculiden und Holothurien*
}

\author{
M. D. HANSEN \\ Institut für Hydrobiologie und Fischereiwissenschaft der Universität Hamburg; \\ Olbersweg 24, D-2000 Hamburg 50, Bundesrepublik Deutschland
}

\begin{abstract}
ABST'RACT: Food and feeding behavior of sediment feeders as exemplified by sipunculids and holothurians. Using a Phillipson microbomb calorimeter, the energy values of the "infauna-substrate-feeders" Sipunculus nudus and Phascolosoma vulgare and the nutritive value of their food substrate were determined. Calorific measurements were made of the total food substrate, of meiofauna organisms living in it and of fecal pellets from other invertebrate animals which are an important part in the food supply. Analyses of the gut content of the sipunculids and their feces were compared with the surrounding sediment. The total sediment had an ash content of about $97 \%$, and an energy content of approximately $0.14 \mathrm{cal} \mathrm{mg}^{-1}$ dry weight; this is equivalent to $165 \mathrm{kcal} \mathrm{m}^{-2}$. For the meiofauna in this substrate a biomass of $800 \mathrm{mg}$ dry weight was calculated. Using calorific determinations of important meiofauna groups (nematodes $5274 \mathrm{kcal} \mathrm{kg}^{-1}$, ostracods 5884 and $6000 \mathrm{kcal} \mathrm{kg}^{-1}$ ), one square meter of the sediment surface - the sipunculid food source - yielded a caloric content of $3.78 \mathrm{kcal}$ for the meiofauna, which means a contribution of $2.3 \%$ to the total food substrate. The largest part of the calorific contents is by far provided by fecal pellets with $0.6 \mathrm{cal} \mathrm{\textrm {mg } ^ { - 1 }}$ dry weight or $150 \mathrm{kcal} \mathrm{m}^{-2}$; this accounts for $92 \%$ of the total calorific content of the food substrate. Peritrophic membranies and attached microorganisms may be responsible for this spectacularly high value. Coprophagy plays an important role. The rest of the total value was contributed by particulate and dissolved detritus as well as protozoans with a calculated sum of $10 \mathrm{kcal} \mathrm{m}^{-2}$ or $6 \%$. Food uptake is selective with regard to small sediment grain sizes. The amount of meiofauna in the gut is 80 times lower than in the surrounding environment, the energy content in the anterior gut 10 times higher. The energy loss in $S$. nudws from the anterior gut to the middle gut is more than $70 \%$, to the posterior gut a further loss of $19 \%$ was observed. Calorific measurements in the feces were no longer possible. The utilization of food appears to be almost $100 \%$. A correlation between ash content and the quantity of the sand grain-size fraction 37-125 $\mu \mathrm{m}$ and the calorific content is shown. The meiofauna does not represent a significant part of the total food structure, but it is taken up and utilized as food by the sediment feeding macrofauna.
\end{abstract}

\section{EINLEITUNG}

Die Organismengemeinschaften in einem Okosystem umfassen verschiedene Lebensformtypen. Unter dem Gesichtspunkt der Nahrungsaufnahme werden in den Assozia-

\footnotetext{
* Dissertation aus dem Fachbereich Biologie der Universität Hamburg.
} 
tionen des marinen Benthos Filtrierer, Strudler, Suspensionsfresser und Sedimentfresser unterschieden. Die Untersuchung dieser Systeme war bisher meistens auf die quantitative Erfassung der Organismenbestände beschränkt. Diese Arbeiten wurden beispielsweise von Boysen Jensen (1919) für den Limfjord und von Muus (1967) für dänische Küstengewässer durchgeführt, ebenfalls urter dem Aspekt potentieller Fischnahrung; sie stellen also rein qualitativ-quantitative, aber nicht energetisch ausgerichtete Erfassungen dar.

Zwei fast klassische Beispiele für die Ermittlung von Energiebilanzen benthischer Organismensysteme sind die Arbeiten von Pamatmat (1968) und Hughes (1970). Analysen einzelner Arten berücksichtigen fast nur den Freßtypus der Filtrierer (z. B. Jørgensen, 1962; Theede, 1963; Boje, 1965; Jørgensen, 1966; Newell \& Bayne, 1973; Foster-Smith, 1975). Hingegen sind für Sedimentfresser Kalorienbestimmungen zur Energiemessung nicht bekannt.

Ziel der vorliegenden Arbeit ist die Erstellung von Energiebilanzen für Sedimentfresser sowie die Erarbeitung von Methoden zur Durchführung von Bilanzierungen für Tiere dieses Freßtypus.

Zur Bearbeitung dieses Problems wurden marine reine Sedimentfresser ausgewählt, die bei einer ausreichenden Größe in ihrer Lebensweise gut zu beobachten waren und präparativ leicht bearbeitet werden konnten. Sipunculiden und Holothurien erwiesen sich als geeignete Organismen, da sie eindeutig nur Sediment aufnehmen. Erste quantitative, jedoch noch nicht energetisch orientierte Untersuchungen wurden von mir an einer Population von Phascolosoma vulgare (de Blainville) von der schwedischen Westküste durchgeführt (Walter, 1973). Für die energetischen Untersuchungen wurde eine Population von Sipunculus nudus (L.) der Atlantikküste ausgewählt, weil der Lebensraum leicht zugänglich war und eine ausreichende Anzahl dieser Sedimentfresser gesammelt werden konnte. Im Lebensraum von $S$. nudus fand sich auch Leptosynapta inhaerens (O. F. Müller), eine Holothurie, an der einige Vergleichsuntersuchungen angestellt wurden.

Die quantitative Analyse des Nahrungsgefüges beinhaltet eine Bestandsaufnahme der im System vorhandenen Nahrungsfaktoren, die den Sedimentfressern zur Verfügung stehen. Aus dem Nahrungssubstrat isoliert erfaßbar sind die "fecal pellets", die in sich einen Teil des Detritus darstellen sowie die Meiofauna. Gleichzeitig kann eine Untersuchung klären, ob die Meiofauna das Endglied einer benthischen Nahrungskette (McIntyre, 1971) bildet und in welchem Maße sie Bedeutung als Nahrungsfaktor hat; letzteres ist ebenfalls für die erwähnten Kotballen im Nahrungssediment zu prüfen.

Zur Erfassung des Energieflusses wurde die Veränderung des Energiegehaltes vom Nahrungssubstrat über den Darminhalt bis zum wieder abgegebenen Substrat gemessen. Für die Gesamtbilanz des Lebensraumes von $S$. nudus wurden die Energiewerte der im untersuchten Gebiet gefundenen Tiere insgesamt bestimmt.

Detritus und Mikroorganismen konnten aus methodischen Gründen nicht gesondert erfaßt werden. Sie wurden durch Subtraktion des Meiofaunaenergiegehaltes von Gesamtenergiegehalt errechnet.

Die Methode der Kalorienbestimmung kann die einzelnen Nahrungskomponenten nur summarisch erfassen, jedoch gilc dieser Nachteil ebenso für andere Verfahren, wie z. B. die Bestimmung von organischem Kohlenstoff. Bei allen Verfahren werden Kohlen- 
stoffverbindungen in die Bestimmung miteinbezogen, die möglicherweise keinen Nahrungswert für die Organismen besitzen. Der Gehalt des Sediments an anorganischem Kalziumkarbonat ist in dem untersuchten Biotop so gering, daß eine Veränderung des Wärmewertes hierdurch vernachlässigt werden kann. Die Erfassung der organischen Substanz der Tiere und des Sediments in Form von Kalorien hat gegenüber den sonst üblichen Biomasse-Meßmethoden den Vorteil, daß hier Angaben des Energiegehaltes gemacht werden (Elmgren, 1973; Elmgren \& Ganning, 1974; Cummins \& Wuycheck, 1971), der in weitere Berechnungen zur Erstellung von Energiebilanzen für ein Ơkosystem eingehen kann.

Die Messung des Energiegehaltes einer trophischen Stufe im System (Lindeman, 1942) stellt allerdings nur eine "Momentaufnahme" eines Energieflusses dar, in dem ein Energietransport und -austausch durch Stoffwechsel oder Dekomposition die verschiedenen trophischen Stufen des Okosystems miteinander verbindet. In dieser Arbeit werden "Momentaufnahmen" im Energiefluß eines Sedimentfressers gegeben: Messungen des Nahrungssubstrats, des Energiegehalts von Vorder-, Mittel- und Enddarm und der Faeces. Diese Bestimmungen erfassen jeweils die gesamte organisch und anorganisch gebundene Energie. Es soll versucht werden zu klären, welcher Anteil der Gesamtenergie von dem Tier genutzt werden kann.

\section{MATERIAL UND METHODEN}

Die vorliegenden Untersuchungen an Sedimentfressern wurden an Sipunculus nudus (Atlantikküste bei Arcachon/Frankreich) durchgeführt. Zum Vergleich bzw. zur Abschätzung der Gültigkeit auch für andere Sedimentfresser wurden Messungen an der Sipunculiden-Art Phascolosoma vulgare (Fundort: Roscoff/Frankreich) und der Holothurien-Art Leptosynapta inhaerens aus dem gleichen Lebensraum wie S. nudus (möglicher Nahrungskonkurrent?) vorgenommen. Die Tiere wurden bei Springtide am Rand der Niedrigwasserlinie aus $20-40 \mathrm{~cm}$ Sedimenttiefe ausgegraben; nur diesem extrem niedrigen Wasserstand kann der Lebensraum dieser Sedimentfresser zu Fuß erreicht werden. Die gesammelten Tiere wurden teilweise sofort in $4 \%$ Formalin in Seewasser überführt, um eine "Weiterverdauung" bzw. weiteren Nahrungstransport im Darmtrakt zu vermeiden. Diese konservierten Exemplare wurden zu Darminhaltsuntersuchungen verwendet. Unkonservierte Tiere wurden sofort nach Aufsammlung im Trockenschrank $\left(60^{\circ} \mathrm{C}, 24\right.$ Std.) für die kalorimetrischen Messungen getrocknet; so vorbereitet wurden ganze Tiere, Darmabschnitte von Tieren sowie die äußere Körperhülle von einzelnen Individuen.

Im Lebensraum der untersuchten Sedimentfresser wurden Bodenproben entnommen, um einen Überblick über das vorhandene Nahrungsangebot zu erhalten. Die Probennahme erfolgte mit dem "Meiostecher" (Thiel, 1966); es wurden Teilproben von $25 \mathrm{~cm}^{2}$ bzw. $10 \mathrm{~cm}^{2}$ und $1 / 2 \mathrm{~cm}$ Einstichtiefe ausgestochen, da die Sedimentoberfläche als Freßort für $S$. nudus erkannt wurde. Die Proben zur Meiofaunazählung wurden mit $4 \%$ Formalin in Seewasser konserviert. Die Korngrößenanalysen wurden an getrocknetem Material vorgenommen. 


\section{Kalorimetrische Bestimmungen}

Das zu kalorimetrierende Material wurde vor der Verbrennung pulverisiert. Die Zerkleinerung erfolgte durch Wolframkarbidkugeln mit einer Schlagmühle Grindomat MM der Firma Retsch KG. Eine Pulverisierung ist erforderlich, um eine möglichst homogene Verteilung des organischen Materials zu erhalten; zudem fördert eine intensive Zerkleinerung die vollständige Verbrennung. Alle kalorimetrischen Bestimmungen wurden mit einem Phillipson Mikrokalorimeter (Phillipson, 1964, Fa. Gentry Instruments Inc., Aiken, USA) durchgeführt. Zur Registrierung wurde ein Kompensationsschreiber, Mikrograph BD 5, der Firma Kipp \& Zonen benutzt. Zur Einwaage der Substanzen diente eine CAHN-G-2-Electrobalance der Fa. Ventron Instruments Corp. Die Füllung der Bombe des Kalorimeters mit reinem Sauerstoff und die Korrektur der angezeigten $\mathrm{mV}$-Werte erfolgten nach den Vorschriften der Herstellerfirma (Gentry \& Wiegert, 1969; Richman, 1971). Endothermische Prozesse können nach Moshiri \& Cummins (1969), Crisp (1971) und Paine (1966) vernachlässigt werden. Korrekturwerte für den Platindraht wurden in die Rechnung miteinbezogen; zusätzlicher Energiegewinn durch die Oxidation des vorhandenen Stickstoffs zu Salpetersäure kann nach Paine (1964) und Moshiri (1968) bei Arbeiten mit dem Phillipson Microbomb Calorimeter ebenfalls vernachlässigt werden, wohingegen bei Arbeiten mit dem Parr-Semimicrobomb-Calorimeter ein Korrekturwert für die Extraenergie empfohlen wird (Kersting, 1972). Konstante Arbeitsbereiche waren ein $\mathrm{O}_{2}$-Füllungsdruck in der Kalorimeterbombe von 35 at, am Kompensationsschreiber $5 \mathrm{~mm} / \mathrm{min}$ Papiervorschub und ein Meßbereich von 0,1 mV-1 $\mathrm{mV}$. Um die Meßgenauigkeit zu ermitteln, wurden 51 Proben zwischen 4,74 mg und 16,12 $\mathrm{mg}$ Einwaage verbrannt. Für diese Messungen ergab sich ein Korrelationskoeffizient von $\mathbf{r}=0,936$. Die gemessene Energie wird in der thermischen Einheit cal angegeben. Die Umrechnung in die elektrische Einheit Joule kann nach $1 \mathrm{cal}=4,186$ Joule bzw. 1 Joule $=0,239 \mathrm{cal}$ erfolgen.

In den Sedimentproben war der Gehalt an organischer Substanz besonders gering. Eine Initialzündung war nur durch Zugabe einer definierten Menge einer leicht brennbaren Substanz von bekanntem Kaloriengehalt möglich. Es wurde nach von Bröckel (1973) in Äthylalkohol gelöste Benzoesäure verwendet. Unvollständig verbrannte Proben, erkennbar an fehlender lockerer, grauer bis orangeroter Asche (je nach Sedimenttyp) wurden verworfen. Die Faeces von Sipunculus nudus wurden sofort nach der Abgabe aus den Hälterungsbecken entnommen, getrocknet und wegen ihres niedrigen Gehalts an organischer Substanz ebenfalls mit Hilfe von Benzoesäure zur Kalorimetrie vorbereitet.

Für die kalorimetrischen Messungen der Meiofauna wurden die ausgesuchten Organismen sofort nach Aussammlung aus dem Sediment 24 Std. bei $60^{\circ} \mathrm{C}$ im Trockenschrank getrocknet.

Zur Messung der Kalorienwerte der Darminhalte der Sipunculiden wurden die Tiere in folgender Weise vorbereitet: die Individuen wurden der Länge nach aufgeschnitten und der an Mesenterien hängende Darm wurde herauspräpariert, ohne das Darmgewebe zu verletzen, um keinesfalls Darminhalt zu verlieren. Nach Tétry (1959) gliedert sich der Darm der Sipunculiden in drei morphologisch und physiologisch zu unterscheidende Teile: Vorderdarm und Oesophagus, Mitteldarm und Enddarm. Entsprechend dieser 
Darmabschnitte wurden die kalorimetrischen Messungen vorgenommen. Der Darminhalt konnte nicht wie bei den Meiofaunauntersuchungen (Goerke, 1971a, b; Walter, 1973) mit Hilfe einer Injektionsspritze mit Sicherheit vollständig vom Darmgewebe getrennt werden. Beim Ausspritzen des Darminhalts in eine Petrischale und besonders bei der Einengung solcher wäßriger kleiner Sedimentproben kann organisches Material verlorengehen. Außerdem können Darmgewebestücke und Schleim in die Probe gelangen und hohe Kalorienwerte für den jeweiligen Darminhalt vortäuschen. Aus diesem Grund wurden von 'Tieren gleicher Gewichtsgruppen bezogen auf das Darmgewicht (die Darmfüllung ist ausschlaggebend für das Gesamtgewicht des Tieres) Parallelmessungen von Darmgewebe mit Darminhalt und Darmgewebe allein durchgeführt. Das Darmgewebe wurde bei $60^{\circ} \mathrm{C} 24 \mathrm{Std}$. getrocknet.

$\mathrm{Zu}$ Beginn der Untersuchungen stellte sich die Frage, inwieweit formol-konserviertes Material für kalorimetrische Messungen geeignet ist. Grundsätzlich wäre es vorteilhaft, wenn konservierte Tiere verwendet werden könnten, da hiermit eine Möglichkeit bestünde, auch solche Proben zu bearbeiten, die nicht speziell zur späteren Kalorimetrie aufbewahrt wurden. Kalorimetrische Messungen an konserviertem Material von S. nudus ergaben unterschiedliche Abweichungen zum unkonservierten Material, und zwar generell niedrigere Werte. Daher sollten solche Proben nicht verwendet werden.

\section{Weitere Untersuchungsmethoden}

Die Meiofauna stellt einen der isoliert erfaßbaren Teile der Nahrung einiger Sedimentfresser dar. Zur Erleichterung des Sortierens wurden die Proben in einem Siebsatz von 100, 63, 42 und $31 \mu \mathrm{m}$ fraktioniert. Die einzelnen Fraktionen wurden anschließend mit Bengalrosa-Phenol eingefärbt (Thiel, 1966) und ausgesucht.

Für die Durchführung der Darminhaltsuntersuchungen wurden die Darmabschnitte aus den aufpräparierten Sipunculiden entleert, die Meiofauna wurde nach Anfärbung ausgesucht. Die ausgesuchten Nematoden wurden mit Hilfe eines Zeichenspiegels in Länge und Durchmesser gemessen, um über Volumenbestimmungen deren Gewicht ermitteln zu können und hierdurch beispielsweise Vergleiche zu möglichen Nahrungskonkurrenten, z. B. der Holothurie Leptosynapta inhaerens, ziehen zu können.

Die Durchführung von Gewichts-, Volumen- und besonders Kalorienwertbestimmungen erweist sich als äußerst schwierig, bedingt durch die geringe Größe und den großen Arbeitsaufwand, der erforderlich ist, um zu einer genügend großen Individuenzahl der jeweiligen taxonomischen Gruppe zu kommen. Auch deswegen sind kalorimetrische Messungen zunächst an Planktonorganismen durchgeführt worden (ausführliche Kalorientabelle bei Prus, 1970); Meiofauna wurde aus den oben erwähnten Gründen nicht berücksichtigt. Anläßlich eines internationalen Arbeitstreffens "Comparison and standardization of work methods in Baltic meiofauna research" im September 1974 in Askö/Schweden, hatte ich Gelegenheit, mit der freundlichen Hilfe der Teilnehmer genügend lebende Meiofaunaorganismen mehrerer Gruppen sammeln zu können. Es liegen daher Untersuchungen über Volumen, Naßgewicht, Trockengewicht und aschefreies Trockengewicht für diese Gruppen vor (Elmgren et al., in Vorbereitung). Die Bestimmungen der Kalorienwerte wurden für Nematoden (6000 Exemplare von kleiner 
bis mittlerer Größe verschiedener Arten) und an den beiden Ostracoden-Arten Cyprideis torosa und Candona spec. (je 500 Exemplare unterschiedlicher Größen) durchgeführt. Es handelt sich hier zum einen um eine Tiergruppe - die Nematoden - mit einer großen Arten- und Größenvarianz, während zum anderen die beiden OstracodenArten sich nur durch eine schmale Größenvarianz auszeichnen.

Die Korngrößenanalysen der Bodenproben wurden nach dem Siebverfahren mit Hilfe eines Siebsatzes (U.S. Standard Sieve Series der Fa. W. S. Tyler International Co., Cleveland 14, Ohio, USA) durchgeführt. Die Maschenweiten der einzelnen Siebe betrugen $500,354,250,177,125,88,63$ und $37 \mu \mathrm{m}$. Eine Korngrößenanalyse des Darminhalts der untersuchten Darmabschnitte war mit Hilfe des standardisierten Siebsatzes nicht möglich, da dieser mit einem Siebdurchmesser von $10 \mathrm{~cm}$ für die anfallenden Sedimentmengen von $15-20 \mathrm{~cm}^{3} \mathrm{zu}$ groß dimensioniert war. Ich benutzte daher einen selbstgefertigten Siebsatz mit $3 \mathrm{~cm}$ Durchmesser mit denselben Maschenweiten.

Alle bisher angeführten quantitativen Untersuchungen beziehen sich auf Sedimentvolumina. Meiofauna und Kotballen wurden aus definierten Sedimentschichten ausgesucht, denn die mit dem Meiostecher genommenen Proben bzw. deren Teilproben haben ein bestimmtes Volumen. Die Volumenbestimmungen der Darmabschnitte bzw. des Gesamtdarmes der Sipunculiden und Holothurien wurden folgendermaßen durchgeführt:

Die aus dem Tier herauspräparierten Darmabschnitte wurden auf Plastikfolie in ihrer Länge mit den vorhandenen Windungen nachgezeichnet, an drei Stellen wurde der Durchmesser des Darmes gemessen. Dabei mußte beachtet werden, daß die Sedimentpackung in den Proben sowohl der verschiedenen Lebensräume wie auch der Darmabschnitte unterschiedlich fest sein kann. Bei gleichmäßiger Darmfüllung konnten die Därme geometrisch und damit rechnerisch als Zylinder angesehen werden und nach $\mathrm{V}=\mathrm{r}^{2} \cdot \pi \cdot \mathrm{h}$ bestimmt werden, wobei $\mathrm{r}$ der durchschnittliche Darmdurchmesser und $\mathrm{h}$ die Länge des Darmes sind.

Um die quantitativen Nahrungsbeziehungen im Biotop wenigstens teilweise $z u$ erfassen, wurden $6 \mathrm{mal}$ aus $1 \mathrm{~m}^{2}$, unter dem bis zu $50 \mathrm{~cm}$ Tiefe die Individuen $S$. nudus und L. inhaerens gezählt wurden, jeweils $5 \times 2$ Bodenproben mit kleinen bzw. großen Meiostechern zur Untersuchung der Meiofauna und der Korngrößenverteilung entnommen. Vier Proben wurden jeweils etwa $10 \mathrm{~cm}$ von den Ecken des Quadrates entfernt gewonnen, die fünfte Probe lag im Zentrum des Quadrates.

Mit der Kenntnis von Darminhalt, Darmvolumen und Energiewerten bei bekannter Darmdurchlaufzeit kann eine Umsatzbestimmung für das jeweilige Biotop durchgeführt werden. Im Rahmen von Hälterungsversuchen wurde die Darmdurchlaufzeit für $S$. nudus bestimmt. Die Tiere wurden in dem natiirlichen Bedingungen entsprechenden Lebensraum ( $9^{\circ} \mathrm{C}$ Wassertemperatur, $33 \%$ Salzgehalt, fließendes Seewasser) gehältert. Die Untersuchungen erfolgten nach 2 Methoden:

Nach der ersten Methode wurden mehrere Individuen von $S$. nudus bestimmten Naßgewichts direkt nach Entnahme aus dem natürlichen Sediment in ein Versuchsbecken mit weißem PVC-Gries (dem Biotop entsprechender Korngrößenzusammensetzung bis 20 Tage in fließendem Seewasser gewässert) gehalten. Nach 24stündigem Aufenthalt im kiinstlichen Sediment mit normalem Freßverhalten wurden die Tiere zurück in Becken mit jeweils natürlichem Sediment gesetzt. Die letzte Faeces-Abgabe 
von PVC-Gries bzw. die erste Faeces-Abgabe von natürlichem Sediment zeigte die Dauer der Darmdurchlaufzeit an. Nach der zweiten Methode wurden die Tiere etwa 30 Minuten in PVC-Sediment gesetzt. Nach intensivem Durchwühlen der PVC-Partikel und deren Aufnahme wurden die Sipunculiden durch Abspülen der PVC-Reste mit Seewasser gereinigt und in natürliches Sediment zurïckgesetzt. Die Abgabe von PVC-Faeces zeigte die Darmdurchlaufzeit an. Das künstliche Sediment war in gleicher Weise wie das natürliche Sediment durch die Darmperistaltik in den einzelnen Darmabschnitten in typischer Weise geformt bzw. zusammengepreßt.

\section{ERGEBNISSE}

\section{Das Nahrungsubstrat}

Die Nahrung der Sipunculiden setzt sich aus Meiofauna, Protozoen, Mikroorganismen sowie partikulärem und gelöstem Detritus zusammen. Von diesen Komponenten können die Meiofauna und vom partikulären Detritus die fecal pellets getrennt erfaßt werden, während die übrigen Bestandteile der Nahrung nur summarisch als Differenz von Gesamtsediment und Meiofauna + fecal pellets angegeben werden können.

\section{Gehalt des Sediments an Meiofauna}

Da die Sipunculiden von der Sedimentoberfläche fressen, wurde nur die oberste Schicht bis $\mathrm{za} 1 / 2 \mathrm{~cm}$ Tiefe der mit kleinen Meiostechern gewonnenen Bodenproben ausgezählt. Bei Untersuchungen zum Bakteriengehalt von Nordseesedimenten wird von Krumbein (1971) eine Schichtdicke von nur 1,5 mm als Sedimentoberfläche angenommen.

Im Lebensraum von Sipunculus nudus wurden an sechs Stellen jeweils fünf Proben pro $\mathrm{m}^{2}$ Sedimentoberfläche entnommen. Die Nematoden stellen den größten Anteil an der Gesamtmeiofauna, gefolgt von Nauplien und den Harpacticiden.

Untersuchungen zahlreicher Autoren (Gray, 1966, 1967; Hartwig, 1973) haben gezeigt, daß der Anteil der kleineren Korngrößen neben der Adsorption von organi-

Tabelle 1

Meiofaunagehalt der Sedimentoberfläche $\left(1 / 2 \mathrm{~cm}\right.$ Sedimenttiefe, Individuenzahl $10 \mathrm{~cm}^{-2}$; $\left.\mathrm{x} 10^{3} \mathrm{~m}^{-2}\right)$

\begin{tabular}{|cccccc|}
\hline $\begin{array}{c}\text { Quadrat- } \\
\text { meter Nr. }\end{array}$ & Proben & Nematoden & Harpacticiden & Nauplien & Diverse \\
\hline I & 5 & $881 \pm 95$ & $101 \pm 10$ & $76 \pm 26$ & $79 \pm 14$ \\
II & 5 & $601 \pm 84$ & $93 \pm 9$ & $100 \pm 11$ & $49 \pm 7$ \\
III & 5 & $60 \pm 12$ & $118 \pm 25$ & $97 \pm 37$ & $30 \pm 10$ \\
IV & 5 & $147 \pm 46$ & $93 \pm 12$ & $121 \pm 30$ & $31 \pm 4$ \\
V & 5 & $394 \pm 124$ & $184 \pm 31$ & $172 \pm 52$ & $89 \pm 21$ \\
VI & 5 & $445 \pm 101$ & $361 \pm 33$ & $886 \pm 139$ & $94 \pm 17$ \\
\hline
\end{tabular}


scher Substanz mitentscheidend für den Nahrungswert eines Sediments ist, denn an der relativ großen Oberfläche und in dem ausgedehnten Lückesystem wachsen viele Bakterien als weitere potentielle Nahrung für sedimentfressende Organismen. Nach Fenchel (1969) besteht eine positive Korrelation zwischen dem Gehalt an organischer Substanz und dem Gehalt an feinen Sedimentpartikeln. Die Durchlässigkeit feiner, dicht gepackter Sedimente für Wasser ist sehr gering, so daß die Oxidation der organischen Substanz nur sehr langsam erfolgen kann.

Besonders die kleineren Korngrößen zwischen 37 und $125 \mu \mathrm{m}$ bieten der Mikrofauna gute Ansatzflächen (Krumbein, 1971). Nach Untersuchungen an Abarenicola pacifica und $A$. vagabunda findet auch Hylleberg (1975), daß die Fraktion $80 \mu \mathrm{m}$ ("fine fraction") im Hinblick auf den anhaftenden Nährwert eine wichtige Fraktion ist und diese Tiere daher auch selektiv diese Fraktion verstärkt aufnahmen. So findet sich in den Untersuchungen auf Grund der Selektivität eine bis zu doppelt so hohe Menge der $80-\mu m-F r a k t i o n$ in den Faeces verglichen mit den Sedimentproben des Nahrungssubstrats. Aus diesem Grunde wird in dieser Arbeit der mit 2,1-3,8\% bestimmte Gewichtsprozentanteil der 37- bis $125-\mu \mathrm{m}$-Korngrößenfraktion des Sediments als Meßzahl für den jeweiligen Sedimenttyp verwendet. Das Sediment für $S$. nudus besteht aus Quarzsand mit Detritusbeimengungen. Für die Sedimentuntersuchungen und Kalorimetrierungen wurden Parallelproben genommen, die in unmittelbarer Nähe zueinander ausgestochen wurden.

Die kalorimetrischen Messungen an Sedimenten, aus denen S. nudus gesammelt wurde, waren wegen des hohen Aschegehaltes der Proben schwierig. Die Ergebnisse von 4 mal 5 Analysen sind in Tabelle 2 als Mittelwerte zusammengestellt.

Tabelle 2

Kaloriengehalt des Nahrungssubstrats (Mittelwerte aus jeweils 5 Bestimmungen)

\begin{tabular}{|c|c|c|c|c|c|}
\hline $\begin{array}{l}\text { Proben-Nr. } \\
\text { und } \\
\text { Einstichtiefe } \\
(0-1 \mathrm{~cm})\end{array}$ & $\begin{array}{l}\text { Trocken- } \\
\text { gewicht } \\
\text { (g) }\end{array}$ & $\begin{array}{l}\text { Asche- } \\
\text { anteil } \\
(0 \%)\end{array}$ & $\begin{array}{l}\text { cal mg-1 } \\
\text { Trodken- } \\
\text { gewicht }\end{array}$ & $\begin{array}{l}\mathrm{cal} \mathrm{mg}^{-1} \\
\text { organische } \\
\text { Substanz }\end{array}$ & $\begin{array}{l}\text { Kalorien- } \\
\text { gehalt } \\
\text { (cal) }\end{array}$ \\
\hline I $(1-5)$ & 12,10 & 98,1 & 0,057 & 3,00 & $690 \pm 23,4$ \\
\hline II $(1-5)$ & 17,06 & 98,2 & 0,007 & 0,39 & $120 \pm 3,7$ \\
\hline III $(1-5)$ & 11,77 & 97,8 & 0,016 & 0,70 & $182 \pm 5,1$ \\
\hline IV $(1-5)$ & 11,44 & 97,5 & 0,017 & 0,67 & $194 \pm 6,5$ \\
\hline
\end{tabular}

Bei der Bestimmung des durchschnittlichen Gesamtkaloriengehaltes wird der hohe Wert von $690 \mathrm{cal} / 5 \mathrm{~cm}^{3}$ aus der Kalkulation herausgelassen. Dieser außerordentliche Wert (16fach höher als die anderen Werte) läßt auf das Vorhandensein eines einzelnen Organismus in der Probe schließen. Die Wahrscheinlichkeit aber, daß ein Sipunculide ein so großes Tier aufnimmt, ist gering.

Das Sediment wird durch seine Korngrößenfraktionen in Gewichtsprozenten charakterisiert. Kalorienwerte werden allgemein auf den Gehalt an organischer Substanz bezogen. Der Kaloriengehalt der obersten Sedimentschicht wurde mit Hilfe von Trokkengewichtsbestimmungen bei Parallelproben errechnet. 


\section{Kalorienbestimmung einzelner Meiofaunaorganismen}

In Tabelle 3 sind die von der working group der "Baltic Marine Biologists" gemessenen Werte zusammengestellt. Zur Bestimmung der Kalorienwerte wurden drei Bestimmungen je Art bei den Ostracoden vorgenommen, wobei die rund 400 gesammelten Exemplare etwa gleichmäßig verteilt wurden. Aus den drei Meßwerten $6779 \mathrm{kcal}$

Tabelle 3

Volumen-, Gewichts- und Kalorienbestimmungen an Meiofaunaorganismen

\begin{tabular}{|lccc|}
\hline Parameter & $\begin{array}{c}\text { Nematoden } \\
\text { (verschiedene mittlere } \\
\text { bis große freilebende } \\
\text { Species) }\end{array}$ & $\begin{array}{c}\text { Cyprideis } \\
\text { torosa }\end{array}$ & $\begin{array}{c}\text { Candona } \\
\text { spec. }\end{array}$ \\
\hline durchschnittliches Volumen & $3 \cdot 10^{6} \mu^{3}$ ind $^{-1}$ & $79,6 \cdot 10^{6}$ & $29,7 \cdot 10^{6}$ \\
Trockengewicht & $1,20 \mu \mathrm{g}$ & $156,9 \mu \mathrm{g}$ & $320,0 \mu \mathrm{g}$ \\
aschefreies Trockengewicht & $0,97 \mu \mathrm{g}$ & $31,6 \mu \mathrm{g}$ & $8,7 \mu \mathrm{g}$ \\
$\% \%$ Trockengewicht & $23,1 \% \%$ & $44,1 \% \%$ & $30,2 \%$ \\
$\% \%$ aschefreies Trockengewicht & $80,6 \%$ \% & $19,6 \%$ & $26,6 \%$ \\
$\mathrm{kcal} \mathrm{kg}^{-1}$ aschefreies Trockengewicht & $5274 \pm 187$ & $6000 \pm 315$ & $5884 \pm 477$ \\
\hline
\end{tabular}

$\mathrm{kg}^{-1}, 5152 \mathrm{kcal} \mathrm{kg}^{-1}$ und $5721 \mathrm{kcal} \mathrm{kg}^{-1}$ aschefreies Trockengewicht bei Candona spec. und $6157 \mathrm{kcal} \mathrm{kg}^{-1}, 5394 \mathrm{kcal} \mathrm{kg}^{-1}$ sowie $6449 \mathrm{kcal} \mathrm{kg}^{-1}$ für Cyprideis torosa ergeben sich als Mittelwerte $5884 \pm 477 \mathrm{kcal} \mathrm{kg}^{-1}$ bzw. $6000 \pm 315 \mathrm{kcal} \mathrm{kg}^{-1}$.

Aus den insgesamt 5660 Nematoden mit dem Trockengewicht von 6,82 mg wurden durch zwei grob geteilte Proben die Kalorienwerte $5087 \mathrm{kcal} \mathrm{kg}^{-1}$ und $5461 \mathrm{kcal}$ $\mathrm{kg}^{-1}$ aschefreies Trockengewicht gewonnen. Der Mittelwert beträgt $5274 \pm 187 \mathrm{kcal}$ $\mathrm{kg}^{-1}$. Für einen einzelnen, durchschnittlich großen Nematoden $(1,20 \mu \mathrm{m}$ Trockengewicht) ergibt sich daraus ein Kalorienwert von $5,1 \times 10^{-3} \mathrm{cal}$.

\section{Kalorienbestimmung von Kotballen}

Die als Kotballen im Sediment identifizierbaren Partikel stammen hauptsächlich von Planktern, aber auch von Benthosorganismen. In diesem Lebensraum mit hoher mechanischer Belastung durch Wellenaktivität werden solche Kotballen schnell zerstört, die nicht durch eine äußere Hülle zusammengehalten werden.

Eine präzise Angabe über die Zahl der fecal pellets pro $\mathrm{m}^{2}$ kann nicht gemacht werden, da ein Erkennen der Kotballen als solche nur bei geformten und von einer Hülle umgebenen fecal pellets möglich ist und daher eine Zählung eine erhebliche Unterschätzung der tatsächlich vorhandenen ergeben würde. Für die Energiewertbestimmungen wurden aus einem Material von rund 12500 geformten fecal pellets mit einem Gesamttrockengewicht von ca. $6 \mathrm{~g}$ fünf einzelne Proben kalorimetriert. Für die fecal

pellets im. Nahrungssediment von Sipunculus nudus ergab sich bei einem Aschegehalt von $87,5 \%$ ein Kaloriengehalt von $5,06 \pm 0,5 \mathrm{cal} \mathrm{mg}^{-1}$ organische Substanz bzw. 0,63 $\pm 0,06 \mathrm{cal} \mathrm{mg}^{-1}$ Trockengewicht. 
In Tabelle 4 sind die Meßwerte für Sediment, Meiofauna und Kotballen zusammengestellt. Durch Differenzierung ergibt sich der prozentuale Anteil bzw. kalorische Wert des Nahrungssubstrats.

Tabelle 4

Energiewerte und prozentuale Verteilung der Nahrungskomponenten

\begin{tabular}{|c|c|c|c|c|}
\hline Komponenten & $\begin{array}{l}\text { cal mg }^{-1} \\
\text { Trodkengewicht }\end{array}$ & $\begin{array}{l}\text { cal mg-1 } \\
\text { organische Substanz }\end{array}$ & $\mathrm{kcal} \mathrm{m}^{-2}$ & $\%$ \\
\hline \multicolumn{5}{|l|}{ Sediment } \\
\hline (I & 0,057 & 3,00 & 690) & \\
\hline II & 0,007 & 0,39 & $120^{\prime}$ & \\
\hline III & 0,016 & 0,70 & 182 & \\
\hline \multirow[t]{2}{*}{ IV } & 0,017 & 0,67 & 194 & \\
\hline & & & $\varnothing 165$ & 100 \\
\hline Meifauna & 4,300 & 5,27 & 3,78 & 2,3 \\
\hline Kotballen & 0,630 & 5,06 & 151,20 & 91,6 \\
\hline $\begin{array}{l}\text { Protozoen, Mikro- } \\
\text { organismen, parti- } \\
\text { kulärer und } \\
\text { gelöster Detritus }\end{array}$ & & & 10,02 & 6,1 \\
\hline
\end{tabular}

Sipunculus nudus

Nach Darstellung des Nahrungsangebotes für den Sedimentfresser Sipunculus nudus sollen Nahrungsaufnahme, -verbleib und -ausnutzung des zur Verfügung stehenden Nahrungssubstrates aufgezeigt werden.

\section{Nabrungsaufnabme - Meiofauna und Kotballen}

Die Nahrungsaufnahme der meisten Sipunculiden-Arten findet von der Sedimentoberfläche her statt; das gilt auch für Sipunculus nudus (zusammenfassende Darstellung bei Tétry, 1959) sowie für die vergleichend untersuchten Individuen der Art Pbascolosoma vulgare. Beobachtungen während der Hälterung der Tiere zeigten, daß S. nudus nach Sedimentaufnahme bis zu $15 \mathrm{~min}$ auf der Sedimentoberfläche liegenbleibt und sich dann vollständig in das Sediment zurïckzieht. Im Darm der Sipunculiden finden sich die gleichen Nahrungskomponenten, wie sie für das Nahrungssubstrat schon beschrieben worden sind.

Meiofauna und fecal pellets stellen diejenigen Nahrungskomponenten dar, die isoliert erfaßbar sind. Darminhaltsuntersuchungen an $S$. nudus sollen zeigen, wieviel dieser Komponenten aus dem zur Verfügung stehenden Sediment aufgenommen wird und in welchen Darmabschnitten deren Verdauung stattfindet.

30 Individuen von $S$. nudus verschiedenen Naßgewichts wurden auf ihren Gehalt an Meiofauna und fecal pellets untersucht. 


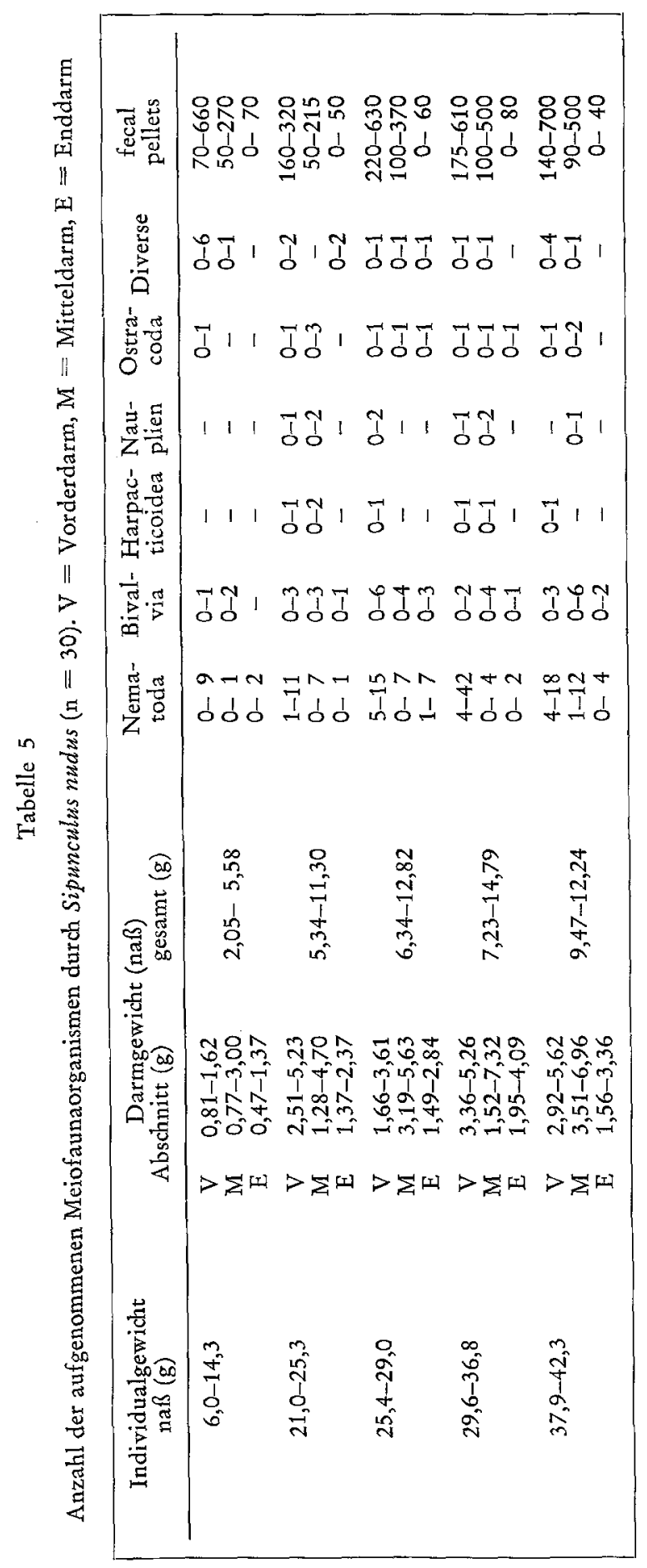


Mit wachsender Körpergröße bzw. zunehmendem Darmvolumen nimmt die Anzahl der aufgenommenen Meiofaunaorganismen zu. Hierbei werden die im feinen Sediment dominierenden Nematoden (Wieser, 1960; McIntyre, 1964; Wigley \& McIntyre, 1964; Muus, 1967; Guille \& Soyer, 1969; Coull, 1969; Stripp, 1969; Tietjen, 1969; Gerlach, 1971; Scheibel \& Noodt, 1975) im Darm am häufigsten gefunden. Die Gruppe, die zahlenmäßig am zweitstärksten vertreten ist, sind die Bivalvia, deren Anzahl mit zunehmendem Gesamtgewicht von $S$. nudus nicht höher wird. Die Bivalvia sind jedoch im Sediment in einer prozentual nicht so großen Anzahl vorhanden; sie werden also in relativ hohem, der Verteilung im Sediment nicht entsprechenden Maße aufgenommen. Die Gruppe der Crustaceen war in Relation zum Lebensraum nur in geringem Umfang vertreten, dennoch zeigte sich mit zunehmender Sipunculidengröße eine geringe Zunahme der aufgenommenen Harpacticiden, Nauplien, Ostracoden und Amphipoden. In der in Tabelle 5 aufgeführten Spalte "Diverse" sind Meiofaunagruppen zusammengefaßt, die in den untersuchten Darmabschnitten der 30 Sipunculiden vereinzelt auftraten. Es wurden Polychaeten, Tardigraden und Halacariden gefunden, Teile von Kolonien von Bryozoen und Hydroiden wurden zwar identifiziert, konnten aber nicht bengalrosa angefärbt werden; sie werden wohl nur als unverdaulicher Ballast mitaufgenommen worden sein.

Von allen ausgesuchten Nematoden wurde mit Hilfe von Länge und Durchmesser das Volumen und daraus das Individualgewicht (nach Wieser, 1960) bestimmt. Eine Abhängigkeit der aufgenommenen Nematoden in ihrer Größe von der jeweiligen Größe des Konsumenten $S$. nudus konnte nicht festgestellt werden. Das gilt sowohl für Länge und Volumen als auch für das Gewicht der Nematoden. Im Gegensatz dazu stehen meine Untersuchungen an der kleineren Art, Phascolosoma vulgare, bei denen die Größe der Nematoden mit zunehmender Größe der Sipunculiden anstieg.

Die fecal pellets zeigen ebenfalls wie die Meiofaunaorganismen eine Abnahme im Verlauf der Nahrung vom Vorder- zum Enddarm. Eine Zunahme der Anzahl bei Zunahme der Individuengröße von $S$. nudus ist nur bedingt feststellbar.

Vergleiche zwischen dem untersuchten Sediment und der daraus entnommenen Nahrung sollten mit Hilfe von Volumen- und Gewichtsbestimmungen ermöglicht werden. Tiere mit einem Individualgewicht zwischen $22 \mathrm{~g}$ und $42 \mathrm{~g} \mathrm{Naßgewicht} \mathrm{hatten}$ Darmvolumina $z$ wischen 11,1 und $27,0 \mathrm{~cm}^{3}$, je nach Füllungszustand des Darmes. Entsprechend variiert auch das Trockengewicht $z$ wischen 4,04 $\mathrm{g}$ and 11,01 g. Mit zunehmendem Gesamtgewicht ergibt sich zum Gewicht der einzelnen Darmabschnitte keine Korrelation, da das Darmgewicht von Intensität und Rhythmus der Nahrungsaufnahme abhängig ist und bei unterschiedlichem Substrat auch von dessen Gewicht. Vergleicht man das unterschiedliche Trockengewicht $(13,6 \mathrm{~g})$ bzw. das Volumen $\left(5 \mathrm{~cm}^{3}\right)$ eines kleinen Meiostechers mit den Gewichtswerten der vorderen Darmabschnitte und dem dort gefundenen Gehalt an Meiofaunaorganismen, so zeigt sich, daß das Nahrungsangebot des umgebenden Sediments durchaus nicht quantitativ aufgenommen wird. Hierbei ist der Meiofaunagehalt des im Darm befindlichen Sediments wesentlich geringer als im Nahrungssubstrat; dennoch ist der Kaloriengehalt des Vorderdarms wesentlich höher als der des Lebenssubstrats. Offensichtlich können fecal pellets und Detritus leichter aufgenommen werden. 


\section{Kalorienbestimmungen von Darmgewebe und Darminhalt}

20 Exemplare von Sipunculus nudus wurden kalorimetrisch untersucht, und zwar (1.) Darmgewebe, (2.) Darmgewebe mit Inhalt, (3.) äußere Körperhülle, (4.) S. nudus gesamt.

$\mathrm{Da}$ es aus präparationstechnischen Gründen nicht möglich ist, von demselben Tier Darmgewebe und davon getrennt den Darminhalt kalorimetrisch zu messen, müssen Vergleichsuntersuchungen an Tieren gleichen Individualgewichts angestellt werden. Wegen der Korrelation zum Gewicht des Nahrungssubstrats wurden von Tieren gleichen Darmgewichts (entscheidend für das Gesamtgewicht des Individuums) sowie dessen Aschegehalt und der Kalorienwert ermittelt.

Der Kaloriengehalt des Darmgewebes von $S$. nudus beträgt durchschnittlich 5,20 cal mg-1 organische Substanz. Der Gesamtkaloriengehalt für das Darmgewebe variiert in Abhängigkeit vom jeweiligen Trockengewicht von 20-227 cal bei 4,2-52,2 mg Trokkengewicht des Darmgewebes und einem Individualgewicht der Sipunculiden von 5,8 bis $48,1 \mathrm{~g} \mathrm{Naßgewicht.}$

Zur Ermittlung der Kalorienwerte der Darminhalte wurde der gesamte Kaloriengehalt des Darmes mit dem darin befindlichen, aus dem Lebenssubstrat aufgenommenen Nahrungssubstrat bestimmt. Der Kaloriengehalt des Darminhalts errechnet sich danach aus der Differenz von Kalorienwert des Darmes (Darmgewebe und Darminhalt) und den Kaloriengehalt des abgetrennten Darmgewebes (siehe Tab. 6).

Tabelle 6

Kaloriengehalt des Darminhalts von Sipunculus nudus

\begin{tabular}{|c|c|c|c|c|c|c|c|}
\hline \multirow[b]{2}{*}{$\begin{array}{l}\text { Individual- } \\
\text { gewicht } \\
\text { naß }(\mathrm{g})\end{array}$} & \multicolumn{2}{|c|}{ Vorderdarm } & \multicolumn{2}{|c|}{ Mitteldarm } & \multicolumn{2}{|c|}{ Enddarm } & \multirow[b]{2}{*}{$\begin{array}{l}\text { Gesamr- } \\
\text { darm } \\
\text { (cal) }\end{array}$} \\
\hline & $\begin{array}{l}\text { cal mg-1 } \\
\text { Darm- } \\
\text { inhalt }\end{array}$ & $\begin{array}{l}\text { Gesamt- } \\
\text { kalorien- } \\
\text { gehalt }\end{array}$ & $\begin{array}{l}\mathrm{cal} \mathrm{mg}^{-1} \\
\text { Darm- } \\
\text { inhalt }\end{array}$ & $\begin{array}{l}\text { Gesamt- } \\
\text { kalorien- } \\
\text { gehalt }\end{array}$ & $\begin{array}{c}\text { cal } \mathrm{mg}^{-1} \\
\text { Darm- } \\
\text { inhalt }\end{array}$ & $\begin{array}{c}\text { Gesamt- } \\
\text { kalorien- } \\
\text { gehalt }\end{array}$ & \\
\hline 5,8 & - & - & 0,12 & 134,36 & - & - & 134,36 \\
\hline 13,9 & 0,41 & 224,86 & - & - & 0,10 & 55,59 & 280,45 \\
\hline 22,5 & 0,17 & 341,07 & - & - & 0,13 & 126,00 & 467,07 \\
\hline 24,0 & 0,29 & 895,53 & 0,17 & 427,03 & - & - & 1322,56 \\
\hline 24,4 & 0,55 & 340,41 & 0,003 & 7,30 & - & - & 347,71 \\
\hline 25,6 & 0,36 & 467,05 & 0,57 & 201,96 & 0,23 & 68,09 & 737,10 \\
\hline 26,2 & 0,33 & 333,16 & - & - & - & - & 333,16 \\
\hline 26,5 & 0,82 & 178,48 & 0,16 & 126,62 & 0,004 & 7,70 & 312,80 \\
\hline 28,0 & 0,32 & 326,47 & 0,01 & 14,69 & 0,01 & 6,98 & 348,14 \\
\hline 28,8 & 0,19 & 330,96 & 0,02 & 44,41 & - & - & 375,37 \\
\hline 30,0 & 0,29 & 187,68 & - & - & 0,002 & 2,01 & 189,68 \\
\hline 31,3 & 0,04 & 61,03 & - & - & - & - & 61,03 \\
\hline 34,9 & 0,26 & 458,62 & 0,03 & 48,44 & - & - & 507,06 \\
\hline 36,0 & 0,34 & 246,02 & 0,02 & 39,72 & - & - & 285,74 \\
\hline 38,0 & 0,58 & 805,09 & - & - & - & - & 805,09 \\
\hline 39,0 & 0,20 & 364,61 & 0,05 & 160,50 & - & - & 525,11 \\
\hline 39,9 & 0,20 & 501,82 & 0,04 & 54,43 & - & - & 556,25 \\
\hline 42,1 & 0,17 & 402,15 & 0,06 & 151,84 & - & - & 553,99 \\
\hline 44,1 & 0,12 & 145,07 & - & - & - & - & 145,07 \\
\hline 48,1 & 0,16 & 417,22 & 0,01 & 28,43 & - & - & 445,65 \\
\hline
\end{tabular}


Die Lücken in der Tabelle 6 bezeichnen solche Versuche, bei denen es nicht möglich war, trotz Hinzugabe von Benzoesäure für die Initialzündung den Verbrennungsvorgang einzuleiten. In diesen Fällen lag der Aschegehalt der Proben über 97,5\%. Wie aus der Tabelle ersichtlich, nimmt der kalorische Gehalt von Abschnitt zu Abschnitt ab; diese generelle Abnahme ist vom Vorder- zum Mitteldarm sehr viel stärker als vom Mittel-zum Enddarm. Die offensichtlich in dieses Schema der generellen Abnahme nicht hineinpassenden höheren Werte für den Energiegehalt in Mittel- und Enddarm lassen sich mit der in diesem Lebensraum zu erwartenden "patchiness" der fleckenhaften Verteilung des Nahrungssubstrats mit unterschiedlichem Gehalt an organischer Substanz, erklären.

Bei einer Betrachtung des Gesamtkaloriengehalts vom Darminhalt bei $S$. nudus wird deutlich, daß die Werte nicht proportional zur jeweiligen Individuengröße zunehmen, obwohl das Gesamtgewicht des Tieres wesentlich durch das Darmgewicht bestimmt wird. Der mittlere Gesamtkaloriengehalt für das Material mit einem Naßgewicht zwischen 5,8 und $48,1 \mathrm{~g}$ beträgt 440 cal. Die Angaben über einen mittleren Gesamtkaloriengehalt sind Integrationswerte über ein außerordentlich heterogenes Material, und zwar (1.) in seiner Zusammensetzung bei Aufnahme aus dem Lebensraum und (2.) verdeckt die Angabe des Kaloriengehalts eines Darmabschnitts, insbesondere beim Vorderdarm, die kleinräumigen Energieveränderungen von der Aufnahme des Nahrungssubstrats bis zum Übergang in den Mitteldarm; dieses außerordentliche Energiegefälle ist bei der notwendigerweise nur möglichen Angabe eines Mittelwertes nicht erkennbar. Daher sollten Betrachtungen des Energiegehalts eines Darmabschnitts in jedem Fall unter Berücksichtigung des Vorhergehenden bzw. Folgenden angestellt werden.

Bezogen auf den Kaloriengehalt pro mg aufgenommenen Sediments ergibt sich für den Vorderdarm 0,305 $\pm 0,0421 \mathrm{cal} \mathrm{mg}^{-1}$ Trockengewicht des Darminhalts, für den Mitteldarm 0,097 $\pm 0,0425 \mathrm{cal} \mathrm{mg}^{-1}$ und für den Enddarm 0,079 $\pm 0,0354 \mathrm{cal} \mathrm{mg}^{-1}$ Trockengewicht.

Der dort zu erkennende Abfall der Kalorienwerte pro mg Darminhalt besonders im Übergang vom Vorder- zum Mitteldarm (um ${ }^{2 / 3}$ bzw. um die Hälfte des Ausgangswertes), aber auch noch im Ubergang vom Mittel- zum Enddarm (19\% bzw. $6 \%$ ), bestätigt noch einmal die Untersuchungen von Tétry (1959) über die Enzymaktivitäten in den einzelnen Darmabschnitten von Sipunculiden. Hiernach setzt die Hauptaktivität der angreifenden Enzyme im Oesophagus-Vorderdarmbereich ein.

\section{Korngrößen, Aschegehalt und Kalorien des Darminhalts}

Vom für die Kalorimetrie verwendeten Darminhalt von S. nudus wurden Paralleluntersuchungen zur Korngrößensortierung durchgeführt. In Tabelle 7 werden für den Vorderdarminhalt der untersuchten. Tiere der Anteil der Korngrößenfraktion 37 bis $125 \mu \mathrm{m}$, der Aschegehalt der aufgenommenen Nahrung und der Kaloriengehalt pro mg Darminhalt nebeneinandergestellt.

Vergleicht man die Fraktion 37-125 $\mu \mathrm{m}$ des aufgenommenen Sediments - von dem ein relativ hoher Gehalt an organischer Substanz erwartet wird - mit den ent- 
Tabelle 7

Korngrößenfraktion 37-125 $\mu \mathrm{m}$, Aschegehalt und Kaloriengehalt im Vorderdarm von Sipunculus nudus

\begin{tabular}{|ccc|}
\hline $\begin{array}{c}\text { Fraktion 37-125 } \mu \mathrm{m} \\
(\%)\end{array}$ & $\begin{array}{c}\text { Aschegehalt } \\
(\% \%)\end{array}$ & $\begin{array}{c}\text { Darminhalt } \\
\left(\mathrm{cal} \mathrm{mg}^{-1}\right)\end{array}$ \\
\hline 38,7 & 79,2 & 0,82 \\
21,3 & 89,3 & 0,29 \\
20,7 & 90,4 & 0,41 \\
16,1 & 91,5 & 0,32 \\
15,4 & 95,2 & 0,16 \\
12,3 & 87,1 & 0,58 \\
11,3 & 95,1 & 0,29 \\
10,3 & 83,2 & 0,55 \\
9,6 & 90,2 & 0,33 \\
9,1 & 89,2 & 0,34 \\
7,0 & 91,0 & 0,36 \\
6,3 & 94,5 & 0,34 \\
6,3 & 94,0 & 0,20 \\
5,9 & 93,2 & 0,19 \\
5,5 & 94,1 & 0,20 \\
5,3 & 93,0 & 0,17 \\
4,1 & 94,6 & 0,12 \\
4,0 & 94,7 & 0,17 \\
3,4 & 93,6 & 0,25 \\
\hline
\end{tabular}

sprechenden Werten für den Kaloriengehalt, so findet man eine deutliche Beziehung zwischen dem Anteil an kleinen Korngrößen und den dazugehörenden Kalorienwerten. Ein hoher prozentualer Anteil der Fraktion 37-125 $\mu \mathrm{m}$ geht parallel mit entsprechend hohem Kaloriengehalt bzw. einem Absinken des Aschegehalts im Vorderdarmabschnitt des Tieres. So hat beispielsweise ein Tier von $14 \mathrm{~g}$ Lebendgewicht einen hohen prozentualen Anteil an der 37- bis 125- $\mu$ m-Korngrößenfraktion mit 20,7 \% und daraus resultierend einen relativ niedrigen Aschegehalt von $90,4 \%$ und einen entsprechend hohen Energiegehalt von $0,41 \mathrm{cal}$ pro mg Nahrungssediment im Vorderdarm. Im Gegensatz dazu hat ein Tier von $44 \mathrm{~g}$ Lebendgewicht einen prozentualen Anteil von 4,1\% der kleinen Korngrößenfraktion, einen Aschegehalt von 94,6\% und daher nur einen Kaloriengehalt von $0,12 \mathrm{cal} \mathrm{mg}^{-1}$ aufgenommenes Sediment.

Die Korngrößenanalysen der drei Darmabschnitte zeigen deutlich, wie die höheren Kalorienwerte im Mittel- und Enddarm zustandekommen, obwohl der höchste Kaloriengehalt im Vorderdarm und eine entsprechende Abnahme in den folgenden Abschnitten zu erwarten gewesen wäre. Die Ergebnisse der Korngrößenanalysen für die einzelnen Darmabschnitte deuten noch einmal auf die breite Streuung der Einzelwerte und die unterschiedlich starke Abnahme des Kaloriengehaltes zwischen den Darmabschnitten hin. Auch eine Zunahme des Kalorienwertes gegenüber dem vorhergehenden Darmabschnitt kann durch die unterschiedlichen Korngrößen teilweise eine Erklärung finden, zumal der Ort der Nahrungsaufnahme und die Korngrößenzusammensetzung des dortigen Sediments unterschiedlich sein kann. In einigen Fällen wurde offensichtlich von einem Sipunculiden zunächst ein Substrat mit hohem Gehalt an der für den Anteil an organischer Substanz mitentscheidenden Fraktion 37-125 $\mu \mathrm{m}$ aufgenommen und später, 
möglicherweise an einem anderen Platz, ein Sediment mit geringerem Anteil an dieser Fraktion. So kann bei prozentual gleicher Nahrungsausnutzung ein hoher Energiewert im Darm weiter fortgeschritten sein als ein niedriger Wert. Dabei ist zu berücksichtigen, daß nicht nur die organische Substanz in Betracht kommt, die direkt an diese Sedimentkomponente gebunden ist, sondern auch der unterschiedliche Gehalt an anderen Nahrungspartikeln und Meiofauna. Die Mittelwerte für die Darmabschnitte können deswegen nur Richtwerte sein. Die Beziehungen zwischen der kleinen Korngrößenfraktion, dem Aschegehalt und dem Kaloriengehalt lassen sich deutlich darstellen. Tiere mit einem Anteil von größer als $10 \%$ an der kleinen Korngrößenfraktion haben einen relativ niedrigen Aschegehalt von durchschnittlich $88,9 \%$ und daraus resultierend einen Kaloriengehalt von $0,43 \mathrm{cal} \mathrm{mg}^{-1}$ Trockengewicht; ein relativ hoher Wert verglichen mit $0,22 \mathrm{cal} \mathrm{mg}^{-1}$ Trockengewicht, gemessen an Tieren mit entsprechend hohem Aschegehalt von $93 \%$ und dem zur ersten Gruppe im Gegensatz stehenden Anteil von kleiner als $10 \%$ an der kleinen Korngrößenfraktion 37-125 $\mu \mathrm{m}$.

\section{Faeces-Untersuchungen}

Letzte Phase des Verlaufs der Nahrung durch den Darm ist die Abgabe der Faeces. Die Faeces der Sipunculiden unterscheiden sich nicht von dem umgebenden Sediment. Sie sind nicht, wie für Crustaceen und Mollusken beschrieben (Arakawa, 1970; Moore, 1931a, b) von einer mucoidartigen, die Faeces zu fecal pellets formenden peritrophischen Membran umgeben. Die untersuchten Kotmengen wurden bei der Hälterung der Tiere in Seewasser ohne Sediment sofort nach Abgabe "frisch" gesammelt und für die Untersuchungen auf Meiofauna formol-konserviert sowie für die Kalorienbestimmungen getrocknet. Sofortige Absammlung der Faeces ist erforderlich, um möglichst einen Abbau der organischen Substanz durch Bakterienbesatz sowie die Lösung noch erfaßbarer Stoffe zu verhindern.

Untersuchungen von 10 Faeces-Proben auf Meiofaunagehalt verliefen negativ. In keiner der Proben wurden Meiofaunaorganismen gefunden.

Ebenfalls 10 Faeces-Proben wurden für kalorimetrische Untersuchungen vorbereitet. Trotz Hinzugabe von Benzoesäure als Zündungshilfe bei jeweils 3 Versuchen war es in keinem Fall möglich, einen kalorischen Wert für die Faeces von Sipunculus nudus zu erhalten. Wie schon erwähnt, bereitete es Schwierigkeiten, Enddarmmaterial zur Zündung zu bringen; hier deutet sich schon an, daß in den Faeces der Gehalt an verbrennbarer Substanz so gering ist, daß eine Bestimmung des möglicherweise noch vorhandenen äußerst geringen Energiewerts auch mit einem Mikrokalorimeter nicht mehr möglich ist. Einen Hinweis auf den Gehalt an organischer Substanz gibt jedoch der hohe Aschegehalt mit durchschnittlich 99,2 $\pm 0,3 \%$ als Mittelwert aus 30 Einzelbestimmungen. Die Verbrennungen im Microbomb-Kalorimeter waren höchstens bei Sedimentproben mit bis zu 98,3\% Aschegehalt möglich. Anhand der Aschegehaltsbestimmungen ergibt sich also für den Gehalt an organischer Substanz in den Faeces ein Anteil von etwa $1 \%$. Da im Enddarm bei einem Kaloriengehalt von 0,0024 cal $\mathrm{mg}^{-1} \mathrm{Darm}$ inhalt noch Messungen möglich waren, muß der Kaloriengehalt der Faeces noch geringer sein. Der durchschnittliche Aschegehalt des Enddarms von $S$. nudus beträgt 97,9\%, 
so daß zwischen dem Substrat im Enddarm und den Faeces eine weitere Energieabnahme von etwa $1 \%$ festzustellen ist.

\section{Bestimmung der Darmdurchlaufzeit}

Für eine Betrachtung der Nahrungsverwertung durch das einzelne Tier sowie des Gesamtumsatzes innerhalb einer in diesem Biotop lebenden Population ist die Bestimmung der Darmdurchlaufzeit erforderlich, die mit 2 verschiedenen Methoden durchgeführt wurde. Die Ergebnisse beider Meßreihen gleichen sich, so daß beide Methoden als geeignet angesehen werden können. Nach Untersuchungen an 8 Tieren mittlerer Größenklasse ergab sich eine mittlere Darmdurchlaufzeit von $19 \pm 1,5$ Stunden bei einer Wassertemperatur von $10^{\circ} \mathrm{C}$. Der Durchschnittswert von 19 Stunden entspricht den Untersuchungen von Romijn (1946), der für Sabella pavonina (Annelida) bei ähnlich zusammengesetzter Nahrung und einer Wassertemperatur von $16^{\circ} \mathrm{C}$ eine Darmdurchgangszeit von 22 Stunden angibt.

\section{Kalorienbestimmung des Gesamttieres}

Eine Bestimmung des Energiegehaltes des Sedimentfressers Sipunculus nudus als Gesamttier wurde im Hinblick auf dessen Bedeutung als Nährtier für größere Organismen durchgeführt. Wenn $S$. nudus bei Wasserbedeckung des Biotops, wie bei der Hälterung beobachtet, in ganzer Länge auf dem Sediment liegt, können beispielsweise Fische die Tiere als ganzes aufnehmen bzw., wenn $S$. nudus seinen Rüssel herausstreckt, können Fische - ähnlich wie sie mit herausgestreckten Muschelsiphonen vorgehen - das Vorderteil anfressen. Lebendbeobachtungen im Labor zeigten, daß auch decapode Krebse wie Carcinus maenas Sipunculiden fressen, und zwar halten sie diese mit ihren Scheren an einem Ende fest und beginnen dort, ihre Beute langsam zu zerkauen. Dabei werden nicht alle Teile gefressen; die Körperflüssigkeit geht dabei verloren und vermutlich wird auch der Darminhalt nicht aufgenommen.

Unter dem Aspekt als Nährtier wurde S. nudus als Gesamttier auf seinen Energiewert hin untersucht; der Gesamtkaloriengehalt gibt Auskunft über den Anteil der Sipunculiden am "standing stock" des untersuchten Biotops. Mit steigendem Lebendgewicht nimmt erwartungsgemäß der Gesamtkaloriengehalt zu, geprägt weniger durch zunehmenden Darminhalt als durch die wachsende Körperhülle. Tiere mit einem Individualgewicht von $14,5 \mathrm{~g}$ hatten einen Gesamtkaloriengehalt von $5,284 \mathrm{kcal}$; mehr als doppelt soviel, $12,459 \mathrm{kcal}$, wurde für Tiere mit einem Lebendgewicht von $50 \mathrm{~g}$ gemessen. Aus Messungen der äußeren Körperhülle ergibt sich folgende Verteilung: nur $5 \%$ des Gesamtenergiewertes werden durch den Darm, aber $95 \%$ des Nährwerts werden durch die äußere Körperhülle gestellt. Durchschnittlich ergab sich für $S$. nudus ein Energiewert von 5,59 $\pm 0,53 \mathrm{cal} \mathrm{mg}^{-1}$ organischer Substanz. 


\section{Phascolosoma vulgare}

In Ergänzung zu den Untersuchungen von Sipunculus nudus wurde die kleinere Sipunculiden-Art, Phascolosoma vulgare, auf den Grad der Nahrungsnutzung untersucht. Die Analysenmethoden gleichen denen von S.nudus.

Die Tiere $(4,5 \mathrm{~cm}-7,4 \mathrm{~cm})$ wurden in fünf Größengruppen eingeteilt. Darminhaltsuntersuchungen wurden nur an Tieren der unterschiedlichen Größengruppen durchgeführt, da ausführliche Untersuchungen über den Darminhalt von $P$. vulgare bereits von mir (Walter, 1973) an Material aus dem Gullmarsfjord/Schweden beschrieben wurden. Es galt also, nur eine Bestätigung für das an der Atlantikküste in einem etwa gleichen Lebensraum für mich gesammelte Material zu finden.

Wie in den früheren Untersuchungen an 75 Individuen von Phascolosoma vnlgare, so deutet sich auch hier eine Zunahme der Meiofaunaanzahl im Darm der Sipunculiden mit zunchmender Individuengröße an. Die größten Tiere nehmen bis zu 3 Nematoden auf, während die kleineren Tiere höchstens einen Nematoden im Vorderdarm enthalten. Bei den großen Tieren wurden auch 1 bzw. 2 Harpacticiden gefunden.

Zur Bestimmung der Kalorienwerte wurden 28 Exemplare präparativ wie $S$. nudus vorbereitet. Der Kaloriengehalt des Darmgewebes von $P$. vulgare beträgt durchschnittlich 5,52 cal mg-1 organische Substanz. Der Gesamtkaloriengehalt variiert in Abhängigkeit vom jeweiligen Trockengewicht von 6,24-24,84 cal bei 1,3-4,3 mg Trockengewicht des Darmgewebes in den Größengruppen 4,5-5,9 cm und 6,0-7,4 cm. Der durchschnittliche Kaloriengehalt des Darminhalts beträgt im ersten Darmabschnitt $0,40 \pm 0,052$

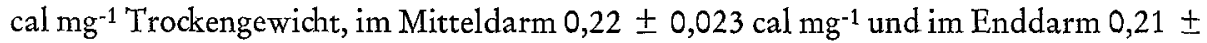
$0,016 \mathrm{cal} \mathrm{mg}^{-1}$ Trockengewicht.

Wie für $S$. nudus, zeigt sich auch bei den Untersuchungen am Darminhalt von $P$. vulgare, wenn auch nicht ganz so deutlich, eine Abnahme des Kaloriengehaltes des aufgenommenen Sediments in den Darmabschnitten vom Vorder- zum Enddarm. Allerdings läßt der im Vergleich zu $S$. nudus relativ höhere Energiegehalt im Enddarm noch eine Kalorienbestimmung zu.

Ein Vergleich der beiden Sipunculiden-Arten (Tabelle 8) zeigt, daß S. nudus die aufgenommene Nahrung weit besser ausnutzt als $P$. vulgare.

Der höhere kalorische Wert des Vorderdarminhalts von $P$. vulgare läßt - bezogen auf $S$. nudus - auf ein energiereicheres Nahrungsangebot oder einen effektiveren Nahrungsauswahlmodus schließen. Im Nahrungssubstrat liegt der Anteil der Korngrößenfraktion 37 bis $125 \mu \mathrm{m}$ im Biotop von $P$. vulgare mit 5,8-7,6\% am Gesamtsediment höher als bei $S$. nudus, dementsprechend liegt auch der Ascheanteil mit durchschnittlich $91 \%$ bei Phascolosoma gegenüber $97 \%$ bei Sipunculus und damit auch der kalorische Wert des Nahrungssubstrats mit durchschnittlich $3,42 \mathrm{cal} \mathrm{mg}^{-1}$ organische Substanz gegenüber $0,59 \mathrm{cal} \mathrm{mg}^{-1}$ weitaus höher. Das Nahrungsangebot für $P$. vulgare ist offensichtlich energiereicher.

\section{Leptosynapta inbaerens}

Im Lebensraum von Sipunculus nudus wurde auch die Holothurie Leptosynapta inhaerens gefunden. Die Darminhalte dieser in etwa gleicher Anzahl pro $\mathrm{m}^{2}$ vorkom- 
Tabelle 8

Zusammenstellung und Ergebnisse zum Nahrungssubstrat von Sipunculus nudus, Leptosynapta inbaerens und Phascolosoma vulgare

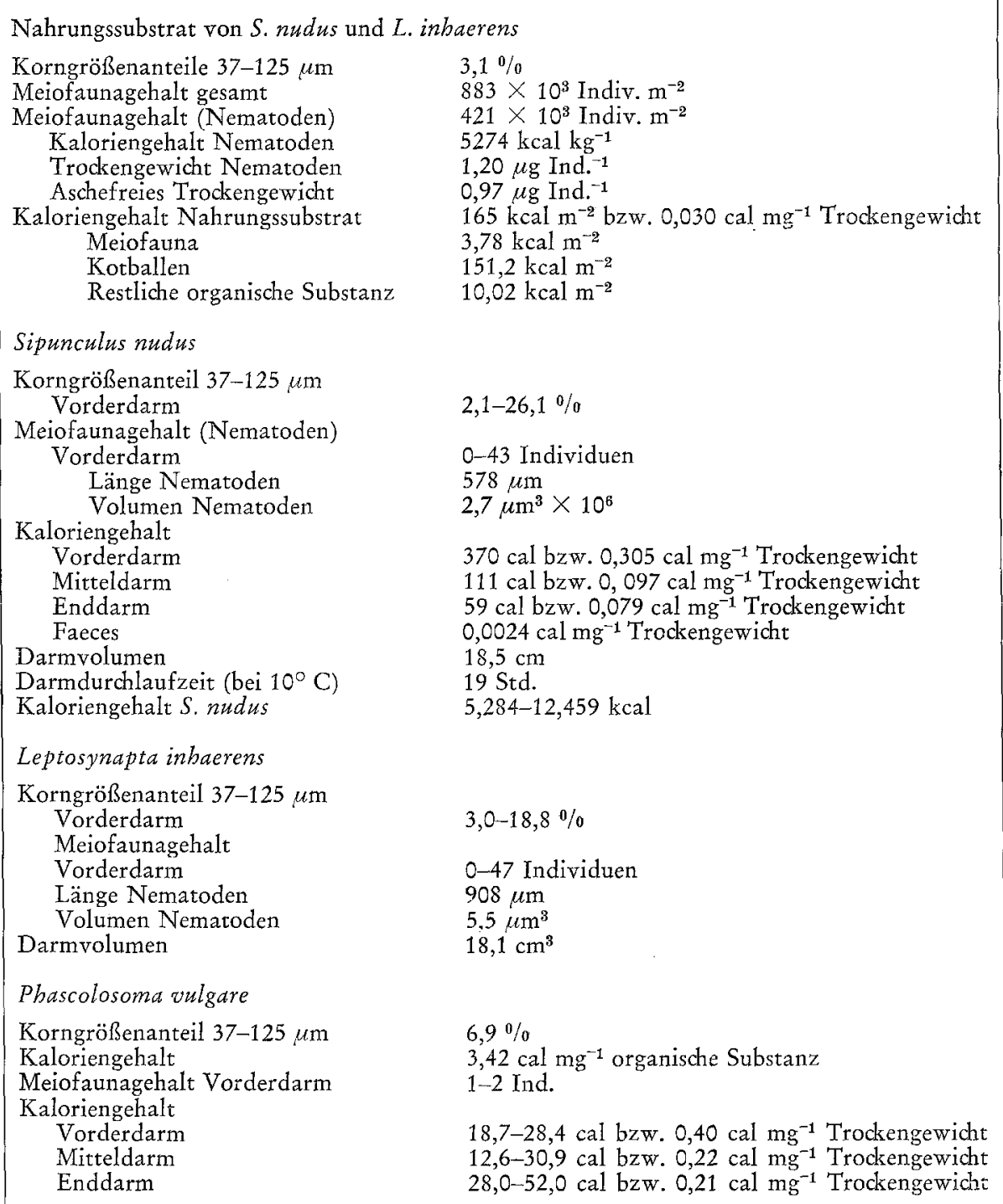

menden Sedimentfresser wurden mit denen von $S$. nudus verglichen, um die Möglichkeit einer eventuellen Nahrungskonkurrenz zu prüfen bzw. die Annahme zu bestätigen, daß zwar der Aufenthaltsraum der Sipunculiden und Holothurien zeitweise identisch ist (bei Ebbe $30-40 \mathrm{~cm}$ Sedimenttiefe), daß die Tiere aber ihre Nahrung in unterschiedlichen Sedimenthorizonten fressen. Die Sipunculiden fressen von der Sedimentober- 
fläche; es ist zwar nicht anzunehmen, daß die Holothurien ständig an ihrem Fundort fressen, aber sie halten sich ständig im Sediment auf und durchbrechen zur Nahrungsaufnahme nicht die Sedimentoberfläche.

Die Meiofaunauntersuchungen konnten quantitativ keinen Unterschied zur aufgenommenen Menge durch S. nudus zeigen. Bei den Untersuchungen des Vorderdarms wurden neben den im Nahrungssubstrat verteilten Meiofaunaorganismen parasitische Copepoden in den Darmfalten und in allen drei Darmabschnitten parasitische Turbellarien gefunden. Diese Darmparasiten ließen kalorimetrische Messungen nicht zu, da Analysen solcher Darminhalte nicht die wahren Energieverhältnisse repräsentieren; zudem ist der Anteil der Verdauung des Nahrungssubstrats durch diese Parasiten nicht bekannt.

Der Vergleich L. inhaerens mit $S$. nudus zur Untersuchung möglicher Nahrungskonkurrenz umfaßt neben Meiofauna-, Volumen- und Gewichtsuntersuchungen auch die Korngrößenanalysen der aufgenommenen Sedimente. Die prozentuale Zusammensetzung der Korngrößenfraktionen kann einerseits etwas über eventuelle Selektivität der Aufnahme gegenüber dem Nahrungssubstrat und andererseits etwas über die Größenordnung der organischen Substanz aussagen, dessen Höhe auch mit der relativen Korngröße zusammenhängt. Die Untersuchungen zeigten, daß die kleineren Exemplare von $L$. inhaerens (10-13 g Lebendgewicht) noch einen relativ hohen Anteil (bis $19 \%$ ) der kleinen Korngrößenfraktion 37-125 $\mu \mathrm{m}$ aufnehmen, die größeren Holothurien jedoch durchschnittlich nur 5,5\%. Mit Hilfe der Meiofaunauntersuchungen und der Korngrößenanalysen kann man den Freßbereich dieser Holothurien eingrenzen. Die Korngrößenanalysen im Vorderdarm von $L$. inbaerens lassen einerseits darauf schließen, daß das Nahrungsangebot nicht von der Oberfläche aufgenommen wird, andererseits kann aber auf Grund des relativ hohen Anteils der aufgenommenen Meiofauna ein Freßhorizont direkt unter der Sedimentoberfläche angenommen werden.

\section{DISKUSSION}

Untersuchungen zur Struktur und Funktion von Lebensgemeinschaften des Benthos erfordern unter anderem eine Klärung der Nahrungszusammenhänge der einzelnen Komponenten, der Sedimentfresser, der Suspensionsfresser und der Räuber.

Filtrierende Organismen, besonders solche aus dem Bewuchs von Hartsubstraten, sind häufig untersucht worden, wie beispielsweise Mytilus edulis (u. a. Boje, 1965; Jørgensen, 1962, 1966).

Für die Untersuchungen aller Sedimentfresser und planktischer sowie benthischer Filtrierer besteht die Schwierigkeit, die verschiedenen Nahrungskomponenten voneinander zu trennen, um deren jeweiligen Anteil am Energiehaushalt ermitteln zu können. Insbesondere ist es das "Detritusproblem", die Trennung der Energie, die an tote organische Bestandteile gebunden ist, von demjenigen Anteil, der mit lebenden Organismen aufgenommen wird.

Eine Begründung für die unterschiedliche Forschungsaktivität auf den Gebieten von Plankton und Benthos liegt nicht im Nahrungssubstrat, sondern vielmehr im "Lebenssubstrat". Plankton und Nekton können aus ihrem Lebensraum herausgefiltert 
werden und stehen dann für die weitere Bearbeitung zur Verfügung. Im Gegensatz dazu besteht eine Benthosprobe aus den Organismen in ihrem Lebenssubstrat, aus dem sie mühsam herausgelesen werden müssen. Hiermit sind auch die geringe Probenzahl, die in einem bestimmten Zeitraum ausgewertet werden kann, und daher auch häufig ein eingeschränkter Aussagewert verbunden. So liegt auch eine Begrenzung in der Aussage dieser Arbeit in einer relativ geringen Anzahl der untersuchten Organismen und Sedimentproben.

Für die Untersuchungen zur vorliegenden Arbeit wurden die Sipunculiden ausgewählt, weil sie als reine Sedimentfresser für besonders geeignet gehalten wurden. Auf Grund der Darminhaltsuntersuchungen kann Sipunculus nudus als "infauna substrate feeder" bezeichnet werden. Die von Blegvad (in Yonge, 1928) angegebene Zuordnung der Sipunculiden zu den "true detritus eaters" erscheint nicht ausreichend charakteristisch, da zwar Detritus in hohem Maße mitaufgenommen wird, diese Nahrungskomponente aber nicht, wie später zu belegen ist, selektiv aus dem Nahrungssubstrat herausgenommen wird. Zudem werden auch Meiofaunaorganismen, wie die Darminhaltsuntersuchungen zeigten, aufgenommen und als Nahrung genutzt, so daß diese Komponente in der Bezeichnung des Freßtypus erwähnt werden sollte. Es erscheint daher die Klassifizierung "infauna substrate feeder" korrekter. Das gilt nach unseren heutigen Erkenntnissen für die im Sediment lebenden Sipunculiden und einige Holothurien.

Die Sedimentfresser unterscheiden sich von den Filtrierern dadurch vorteilhaft, daß sie das gesamte Substrat in ihren Darmkanal aufnehmen, auch wenn kleine Korngrößenanteile gegebenenfalls bevorzugt werden. Die Filtrierer hingegen können einen Teil der filtrierten Partikel als Pseudofaeces abgeben, ohne daß diese durch den Darm gegangen wären. Zudem entspricht bei den Substratfressern das Nahrungssubstrat dem Lebenssubstrat.

In die weitere Diskussion werden die Ergebnisse aus der Gesamtübersicht in Tabelle 8 zur Kalkulation und zur Wertung der energetischen Beziehungen im bearbeiteten Ơkosystem einbezogen.

Um zu einer Abschätzung des Umsatzes in einem begrenzten Gebiet zu kommen, muß zunächst der "Ist-Stand" der Zusammensetzung der Lebensgemeinschaft aus den vorhandenen Komponenten erfaßt werden. Wesentlich ist auch die Kenntnis darüber, welchen Anteil die einzelnen Komponenten des Substrates an der Nahrung der Sedimentfresser haben.

Der Gesamtenergiewert wie auch dessen Zusammensetzung ist kleinräumigen, in Tideneinflußbereichen besonders ausgeprägten Veränderungen unterworfen.

\section{Die Meiofauna im Nahrungsubstrat}

Die für die Untersuchung der Meiofauna ausgestochenen Sedimentproben umfaßten in ihren Flächen mit $10 \mathrm{~cm}^{2}$ und der Einstichtiefe von $0,5 \mathrm{~cm}$ ein Volumen von $5 \mathrm{~cm}^{3}$; dieses entspricht etwa einer Vorderdarmfüllung von $S$. nudus mittlerer Größe, die angegebenen Werte sind also später mit den Vorderdarmabschnitten von Sipunculus nudus direkt vergleichbar. In Tabelle 9 sind die in der vorliegenden Untersuchung ermittelten Werte für die Meiofauna zusammengestellt. 
Für $1 \mathrm{~m}^{2}$ Sedimentoberfläche in diesem Biotop errechnet sich ein durchschnittliches Trockengewicht von $810 \times 10^{3} \mu \mathrm{g}$ als Biomasse der Meiofauna; die Werte in Tabelle 9 korrespondieren mit den Angaben z. B. von Wieser (1960), Wigley \& McIntyre (1964) und den zusammenfassenden Angaben in Rachor (1975). Diese Biomasse hat einen bestimmten Energiewert, der den Predatoren als Nährwert zur Verfügung

Tabelle 9

Trockengewicht und Kaloriengehalt der Meiofauna pro $\mathrm{m}^{2}$ und $0,5 \mathrm{~cm}$ Schichttiefe (Arcachon)

\begin{tabular}{|lccccc|}
\hline Organismen & $\begin{array}{c}\text { Trocken- } \\
\text { gewicht pro } \\
\text { Individuum } \\
(\mu \mathrm{g})\end{array}$ & $\begin{array}{c}\text { Kalorien- } \\
\text { gehalt pro } \\
\text { Individuum } \\
\left(\mathrm{cal} \times 10^{-3}\right)\end{array}$ & $\begin{array}{c}\text { Anzahl der } \\
\text { Organismen } \\
\text { pro } 10 \mathrm{~cm}^{3} \\
\left(\times 10^{3} \mathrm{~m}^{-2}\right)\end{array}$ & $\begin{array}{c}\text { Trocken- } \\
\text { gewicht der } \\
\text { Organismen } \\
\left(\mathrm{mg} \cdot \mathrm{m}^{-2}\right)\end{array}$ & $\begin{array}{c}\text { Kalorien- } \\
\text { gehalt der } \\
\text { Organismen } \\
\left(\mathrm{kcal} \cdot \mathrm{m}^{-2}\right)\end{array}$ \\
\hline $\begin{array}{l}\text { Nematoden } \\
\begin{array}{l}\text { Harpacticiden } \\
\text { Ubrige Meiofauna } \\
\text { (überwiegend } \\
\text { Nauplien) }\end{array}\end{array}$ & 1,20 & 5,1 & 421 & 0,51 & 2,15 \\
$\begin{array}{l}\text { Meiofauna } \\
\text { Gesamt }\end{array}$ & 1,90 & 5,1 & 158 & 0,30 & 0,81 \\
\hline
\end{tabular}

steht. Eigene Untersuchungen an Nematoden ergaben für diese Gruppe einen durchschnittlichen Kaloriengehalt von $5274 \mathrm{kcal} \mathrm{kg}^{-1}$ aschefreies Trockengewicht. Nach Cummins \& Wuycheck (1973) enthalten "microconsumers", um die es sich bei der Meiofauna handelt, einen durchschnittlichen Kaloriengehalt von $4958 \mathrm{kcal} \mathrm{kg}^{-1}$ aschefreies Trockengewicht. Die gesamte Biomasse der Meiofauna hat einen Kaloriengehalt von 3,78 kcal $\mathrm{m}^{-2}$, wobei die Nematoden rund $57 \%$ davon stellen. Die nicht meßbare, weil mit der verwendeten Methode nicht erfaßten, sog. "weiche" Meiofauna, ist zahlenmäßig und damit auch in energetischer Hinsicht von geringer Bedeutung.

Die Werte aus den eigenen Untersuchungen stimmen größenordnungsmäßig mit Literaturangaben überein. Beispielsweise wurde in der Arbeit von Brawn et al. (1968) der kalorische Gehalt des "standing stock" von benthischer Makrofauna pro m² Sediment in einer Wassertiefe von $25 \mathrm{~m}$ untersucht. Sie erhielten für den Invertebratenbestand einen Gesamtkaloriengehalt von $8-80 \mathrm{kcal} \mathrm{m}^{-2}$. Ähnliche Werte wurden von Jones (1956) für ein schlammiges Gebiet mit Werten zwischen 27 und $139 \mathrm{kcal} \mathrm{m}^{-2}$ und Wigley \& McIntyre (1964) für verschiedene Lebensräume und Tiefenbereiche für Makro- und Meiofauna mit Werten zwischen 17 und $29 \mathrm{kcal} \mathrm{m}^{-2}$ festgestellt.

Berechnungen für die Meiofauna auf Grund von kalorischen Messungen lagen bisher noch nicht vor. Bei Anwendung der allgemeinen Formel von Odum (1959), daß die Kalorien pro $\mathrm{m}^{2}$, grob abgeschätzt, etwa der Zahl des Trockengewichts in $\mathrm{mg}$ mit dem Faktor 4 multipliziert entsprechen, ergibt sich für die Meiofauna des obersten $1 / 2 \mathrm{~cm}$ bezogen auf die eigenen Untersuchungen, aus $1,05 \mathrm{mg} \mathrm{m}^{-2}$ Trockengewicht $\mathrm{m}^{-2}$ ein Kaloriengehalt von $4,3 \mathrm{kcal} \mathrm{m}^{-2}$; die eigenen Messungen ergaben $3,78 \mathrm{kcal} \mathrm{m}^{-2}$. Dabei konnten nicht alle Organismen des Meiofaunabestandes erfaßt und berïcksichtigt werden. 


\section{Die Kotballen im Nahrungsubstrat}

Der zahlenmäßig und kalorisch größte Anteil im Nahrungssubstrat und auch in der Nahrung wird durch die Kotballen von hauptsächlich planktischen Copepoden, aber auch von benthischen Organismen wie Mollusken, gebildet. Der Energiewert, der von diesen "fecal pellets" gestellt wird, dürfte verschieden hoch sein, wobei auch die drei Bestandteile, die unverdaute Nahrung, die peritrophische Membran und der Aufwuchs unterschiedlich zum Gesamtwert beitragen. Benthische Organismen wie Mollusken geben ihre Faeces zwar geformt und daher als solche unterscheid- und identifizierbar (Moore, 1931; Arakawa, 1970), aber nicht gänzlich von einer Hülle umgeben, ab, so daß an den jeweiligen Bruchstellen sowohl Lösung wie auch Angriff und Abbau noch ungenutzter organischer Substanz durch Bakterien und andere Mikroorganismen möglich sind. Die fecal pellets von Copepoden sind dagegen völlig von einer Hülle umgeben, die vom Enddarm der Tiere produziert wird (Gauld, 1957) und entweder mucoidartig oder chitinartig ist. Schon allein durch diese Hülle können diese Kotballen einen Energiewert darstellen. Sipunculus nudus besitzt chitinangreifende Fermente und kann diese Kotballen abbauen und als Nahrung nutzen. Generell ist der Kaloriengehalt von Faeces im Nahrungssubstrat bei Nahrungsuntersuchungen von Bedeutung. So bietet die Hülle der fecal pellets eine relativ große Ansatzfläche für Bakterien, Mikroflagellaten und Diatomeen. Untersuchungen an Faeces zeigten, daß sie assimilatorisch nutzbare organische Substanz enthalten, die durch den mikrobiellen Abbau der anderweitig nicht verwendbaren Restsubstanz entsteht (Newell, 1965). Der Vorteil für die Sedimentfresser liegt daher nicht nur im Nahrungswert der Bakterien selbst, sondern auch darin, daß diese die in den fecal pellets vorhandene organische Substanz aufschließen oder zu ver wertbarer Substanz transformieren. Bei der Veränderung des Nährwertes der Kotballen spielt auch der Zeitfaktor eine Rolle. In Abhängigkeit von der Abbaugeschwindigkeit der jeweiligen Substanzen befindet sich u. U. weniger nutzbare Energie in den Faeces zum Zeitpunkt der Abgabe als Stunden oder Tage später auf Grund der Bakterienvermehrung bzw. der stofflichen Veränderung. Für ökologische Zwecke erscheint es nach Johannes \& Satomi (1966) sinnvoll, die fecal pellets mit ihrem Aufwuchs als "Organismen" $z u$ betrachten, da sie organische Substanz verbrauchen und umsetzen sowie eine Nahrungsquelle für andere Tiere darstellen; "Populationen" von fecal pellets nehmen quantifizierbar am Energiefluß des marinen Ólsosystems teil. Die Koprophagie aquatischer Faunenelemente spielt cine wichtige Rolle in den trophischen Beziehungen benthischer Tiergruppen (Frankenberg \& Smith, 1967; Frankenberg et al., 1967). Allein für die Kotballen mit ihrem Aufwuchs ergibt sich für das untersuchte Nahrungssediment von $S$. nudus der entscheidende Anteil von bis zu $92 \%$ an dem Gesamtenergiegehalt des Sediments; dieses ist ein Hinweis auf die entscheidende Bedeutung der Kotballen als Nahrungskomponente.

\section{Die übrigen Komponenten des Nahrungssubstrats}

Der Energiegehalt für die übrigen Komponenten des Nahrungssubstrats errechnet sich durch Differenzbildung aus dem Gesamtkaloriengehalt für das Sediment und den 
Energiewerten für die Meiofauna und die Kotballen; er beträgt rund 6\% des Gesamtkaloriengehalts.

Wie bei den Kotballen, so liegt auch der Nutzgewinn des Detritus für den Sedimentfresser weniger im Detritus selbst (Hylleberg, 1975), sondern vielmehr in den aufsitzenden Mikroorganismen, die sich ihrerseits von der im freien Wasser befindlichen bzw. in Aggregationen vorliegenden gelösten organischen Substanzen ernähren. Nach Whitlatch (1974) bevorzugen Polychaeten der Art Pectinaria gouldii Sandkörner mit einer Kruste aus organischem Material, flockige Aggregate und fecal pellets, ein Hinweis auf die wichtige Rolle der partikulären organischen Substanz als Nahrungskomponente.

Bakterien können als Nahrung aufgenommen und energiespeichernd assimiliert werden. Dies zeigte beispielsweise MacGinitie (1932) an Echiuriden, die in einer Bakterienkultur gehalten werden konnten. Darmuntersuchungen an Polychaeten (Hylleberg, 1975) ließen erkennen, daß eine deutliche Reduzierung von freibeweglichen Bakterien und Diatomeen im Rektum im Vergleich zum Oesophagus eintritt.

Die von Sipunculus nudus untersuchte Population lebt im unteren Gezeitenbereich, in dem ein stetiger Wechsel der Strömungsverhältnisse ständige kleinräumige Veränderungen in der Sedimentoberfläche hervorruft. Im Schutz von Hafenbauten ist das Wasser am Sammlungsort relativ ruhig, so daß spezifisch leichtere Partikel als der Sand sedimentieren und sich in den Mulden konzentrieren können. Den Sipunculiden stehen damit Substrate unterschiedlicher Nahrungsqualität, Meiofaunaanzahl und Aschegehalt sowie von unterschiedlichem Energiegehalt zur Verfügung. Beispielsweise liegt der Aschegehalt des Sediments zwischen $96 \%$ und $98 \%$, der mittlere Kaloriengehalt zwischen $0,4 \mathrm{cal} \mathrm{mg}^{-1}$ und $3,0 \mathrm{cal} \mathrm{mg}^{-1}$ organische Substanz bzw. 0,007 cal mg ${ }^{-1}$ und 0,06 cal $\mathrm{mg}^{-1}$ Trockengewicht. Gewichtsvergleiche zeigten, daß ein Sediment mit hohem Energiegehalt, also hoher Nahrungskonzentration, spezifisch leichter ist. So konnte experimentell durch Anreicherung des natïrlichen Sediments mit den feinen Komponenten des natürlichen Substrats der Aschegehalt auf 3,6 cal mg-1 organische Substanz gesteigert werden. Für die Lebendhaltung von Sipunculiden wurde das Sediment in dieser Weise mit Nahrungsstoffen angereichert.

Trotz aller Faktoren, die eine hohe Variabilität in diesem Lebensraum bedingen, war die Untersuchung gerade dieser S. nudus - Population wegen der leichten Erreichbarkeit vorteilhaft.

\section{Nahrungsaufnahme und Energiegehalt im Darm}

Entsprechend dem Tideneinfluß haben die Sipunculiden Freß- und Ruhephasen. Die Nahrung wird schubweise aufgenommen und nahezu unvermischt durch den Darm transportiert; bei Abgabe der Faeces während der Untersuchung zur Bestimmung der Darmdurchlaufzeit ist eine scharfe Trennung zwischen natürlichem Substrat und dem künstlichen PVC-Sediment zu erkennen.

Die Nahrungsaufnahme scheint nicht selektiv im Hinblick auf Nahrungskomponenten eines möglichst hohen Energiegehalts zu sein. Organismen werden nicht bevorzugt gegenïber anorganischen Sedimentpartikeln aufgenommen. Bezüglich der aufge- 
nommenen Korngrößen kann jedoch von einer "eingeschränkten Selektivität" gesprochen werden. Erstens enthält der Darminhalt von Sipunculus nudus mit ca. $10 \%$ mehr als dreimal soviel kleiner Korngrößenanteile, als im Nahrungssubstrat vorhanden sind, zweitens aber können in beachtlichen Mengen fecal pellets aufgenommen werden, obwohl sie größer sind als Sandkörner; ihre Aufnahme wird vermutlich durch das spezifisch leichtere Gewicht und die meist abgerundete, ellipsoide Form begünstigt. Auch im Hinblick auf die Aufnahme von Meiofaunaorganismen zeigt sich kein "echtes" selektives Verhalten. Wie aus meinen früheren Untersuchungen bekannt (Walter, 1973), sind die Sipunculiden in der Lage, eine relativ große Anzahl von Nematoden und kleine Muschellarven aufzunehmen. Diese Tiergruppen sind durch ihre relative Trägheit nicht in der Lage, sich dem Gefressenwerden durch Flucht zu entziehen. Im Gegensatz dazu werden Crustaceen, vor allem größere Individuen, durch die Sipunculiden nur in geringem Maße aufgenommen. Sie können sich durch eine schnelle Fluchtreaktion bzw. Sperrigkeit ihrer Körperform der Aufnahme entziehen. Ostracoden bilden von dieser Regel eine Ausnahme, da viele Arten dieser Meiofaunaorganismen weniger beweglich und sperrig sind.

Die Meiofauna im Vorderdarm ist im Durchschnitt kleiner als im Nahrungssubstrat, und der in der Meiofauna gebundene Gesamtenergiegehalt ist entsprechend geringer. Trotz dieser relativen Energieabnahme ist der Gesamtenergiegehalt im Darm höher als im nichtaufgenommenen Nahrungssubstrat. Die Zunahme des Gesamtenergiegehalts im Vorderdarm um den Faktor 10 ist sicherlich eine Folge der besonders mit den kleinen Korngrößen aufgenommenen Detritusteile und dem damit verbundenen Aufwuchs sowie dem großen Anteil der fecal pellets in der Nahrung.

Vergleicht man die Rolle der Meiofauna in den beiden Sipunculiden-Arten und bei verschiedenen Größen von S, nudus, so ergeben sich unterschiedliche Wertigkeiten für diese Nahrungskomponente in bezug auf das gesamte Nahrungssubstrat, wobei aber in keinem Fall von einer entscheidenden Rolle der Meiofauna an der Nahrung der sedimentfressenden Sipunculiden gesprochen werden kann.

Anhand der Nernatoden, der dominierenden Meiofauna-Gruppe, kann dies erläutert werden: aus dem Nahrungssubstrat (421 Ind. $/ 5 \mathrm{~cm}^{-3}$ ) werden in den Vorderdarm nur 1,4-3,6\% der vorhandenen Nematoden (6-16 Ind./5 $\left.\mathrm{cm}^{-3}\right)$ aufgenommen, vom durchschnittlichen Gesamtkaloriengehalt des Vorderdarms werden bei den kleineren Individuen von $S$. nudus $0,009 \%$, bei den größeren $0,017 \%$ der gemessenen Gesamtenergie von den Nematoden gestellt. Bei der kleineren Art, Ph. vulgare, ist der Wert mit $0,007 \%$ entsprechend noch geringer. Diese Ergebnisse über die Rolle der einzig lebenden größeren Komponente im Nahrungssubstrat wurden schon für Arenicola marina nach Darminhaltsuntersuchungen vermutet. Krüger (1971) nimmt an, daß größere Organismen nicht entscheidend in der Nahrungsbilanz sein können; er vermutet, daß es Mikroorganismen sein müssen, von denen sich $A$. marina im wesentlichen ernährt. Die Frage einer Nahrungskonkurrenz von $S$. nudus und L. inhaerens kann möglicherweise durch einen Vergleich der prozentualen Korngrößenverteilung im Vorderdarm der Sedimentfresser beantwortet werden. Beide Arten haben unterschiedliche Freßhorizonte: S. nudus nimmt seine Nahrung von der Sedimentoberfläche auf, während dort der prozentuale Anteil der Korngrößenfraktion 37-125 $\mu \mathrm{m}$ bei 3\% liegt, steigt die Häufigkeit dieser Partikel im Vorderdarm bis zu 39\% an. Eine Erklärung hierfür 
ist in der bevorzugten Aufnahme feiner Sedimentteile und Kotballen, die sich oberflächlich in Mulden des Sediments sammeln, zu sehen. L. inbaerens frißt nahe der Sedimentoberfläche - dies zeigen die zu S. nudus kaum verschiedenen Meiofaunazahlen aber in einem etwas tieferen Sedimentbereich, abzulesen am Anteil der kleinen Korngrößenfraktion mit im Höchstfall $6 \%$, da die lokale Konzentration feiner Partikel mit den momentanen Bedingungen der Wasserbewegungen entfällt.

\section{Nahrungsadsorption im Darm}

Nach der Nahrungsaufnahme durchläuft das Substrat den Darm der Tiere. Die Morphologie und die physiologischen Leistungen des Darms der Sipunculiden wurden von Tétry (1959) zusammengefaßt: Das Nahrungssubstrat tritt nach seiner Aufnahme in den Oesophagus-Bereich, der eine strikt mechanische Funktion hat, ein in den zweiten Teil des Vorderdarms, den Beginn der absteigenden Darmspirale. Dort finden Verdauung und Adsorption der Nahrung statt. Die eigentliche Darmspirale, als Mitteldarm definiert, und auch der Enddarm dienen nur der Adsorption. Bei Sipunculus nudus beträgt die prozentuale Abnahme des Energiegehalts des aufgenommenen Sediments auf dem Weg vom Vorder- zum Mitteldarm $68 \%$; zwischen Vorder- und Enddarm nimmt die Anfangsenergie um $74 \% \mathrm{ab}$, und bis $\mathbf{z u}$ den Faeces wird die Nahrung um praktisch $100 \%$ ausgenutzt. Der Grad der Ausnutzung der aufgenommenen organischen Substanz ist also außerordentlich hoch. Auch aus dem Enddarm wird Energie aufgenommen, wie sich aus der Energieabnahme zwischen Enddarm und Faeces nachweisen läßt. Da der Gehalt der Faeces an organischer Substanz bei knapp $1 \%$ lag und damit für eine kalorimetrische Bestimmung zu gering war, konnten keine Energiewerte der Faeces von $S$. nudus gemessen werden, während ein Energiegehalt im Enddarm dagegen durchaus noch nachweisbar und meßbar war. Ausgehend vom aschefreien Trockengewicht läßt sich der Energiegehalt der Faeces auf kleiner als $0,0024 \mathrm{cal} \mathrm{mg}^{-1}$ Sediment (kleinster für einen Enddarmabschnitt mit dem Mikrokalorimeter noch meßbarer Wert) abschätzen. Es ist allerdings auch damit zu rechnen, daß ein Teil der organischen Substanz, der bei der Kalorimetrie erfaßt wird, durch diese Tiere nicht zersetzbar und nutzbar ist und daher mit den Faeces wieder ausgeschieden wird.

Die Energienutzung ist bei der kleineren Art, Phascolosoma, offensichtlich nicht so groß. Im Enddarm beträgt der Kaloriengehalt noch $47 \%$ des Vorderdarm-Energiegehalts. Eine hohe Nahrungsausnutzung ist bei diesem Sedimentfresser möglicherweise auch weniger bedeutsam, da der Boden in 12-15 m Tiefe schlammig ist und einen hohen Detritusgehalt verbunden mit hohem Gehalt an der Korngrößenfraktion 37-125 $\mu \mathrm{m}$ aufweist. Damit steht den Tieren ständig energetisch reichhaltige Nahrung zur Verfügung; durch einen Tidenwechsel aufgeprägte Ruhephasen sind nicht vorhanden. Die Abnahme des Energiegehaltes zwischen den Darmabschnitten ist nicht immer so deutlich; in einigen Fällen kehrt sich das Verhältnis sogar um, so daß für Mittel- und Enddarm ein höherer Energiewert als für den vorhergehenden Darmabschnitt gemessen wurde. Ursache für dieses zunächst unerwartete Ergebnis dürfte die starke Variabilität im Lebensraum sein, auf die wiederholt hingewiesen ist; auf Grund dieser Tatsache können sich Partikelgröße, Fauna und Energiegehalt sehr stark unterscheiden. Der 
einzelne Sipunculide findet kleinräumige Unterschiede im Nahrungsangebot seines Lebensraumes; er nimmt dementsprechend in unregelmäßiger Folge Nahrung mit mehr oder weniger hohem Energiegehalt auf. Die Variabilität in den Meßwerten wird an diesem Beispiel noch einmal deutlich.

Zusätzlich geht bei diesen Ergebnissen der Zeitfaktor der Probennahme mit ein, der durch die Dauer zwischen Nahrungsaufnahme und Konservierung des Untersuchungsmaterials bestimmt ist. Je länger dieser zeitliche Abstand ist, um so geringer dürfte der Kaloriengehalt wegen der fortlaufenden Adsorption von Energie im Darm sein. Die Energiewerte für die drei Darmabschnitte und zwischen den verschiedenen Individuen sind also nicht ohne Einschränkung miteinander vergleichbar; trotzdem müssen diese Mittelwerte als Integrationswerte über die Darmabschnitte für eine Bilanzierung verwendet werden. In Abbildung 1 sind noch einmal die für die Nahrunsbilanz von $S$. nudus bestimmenden Ergebnisse zusammengestellt.

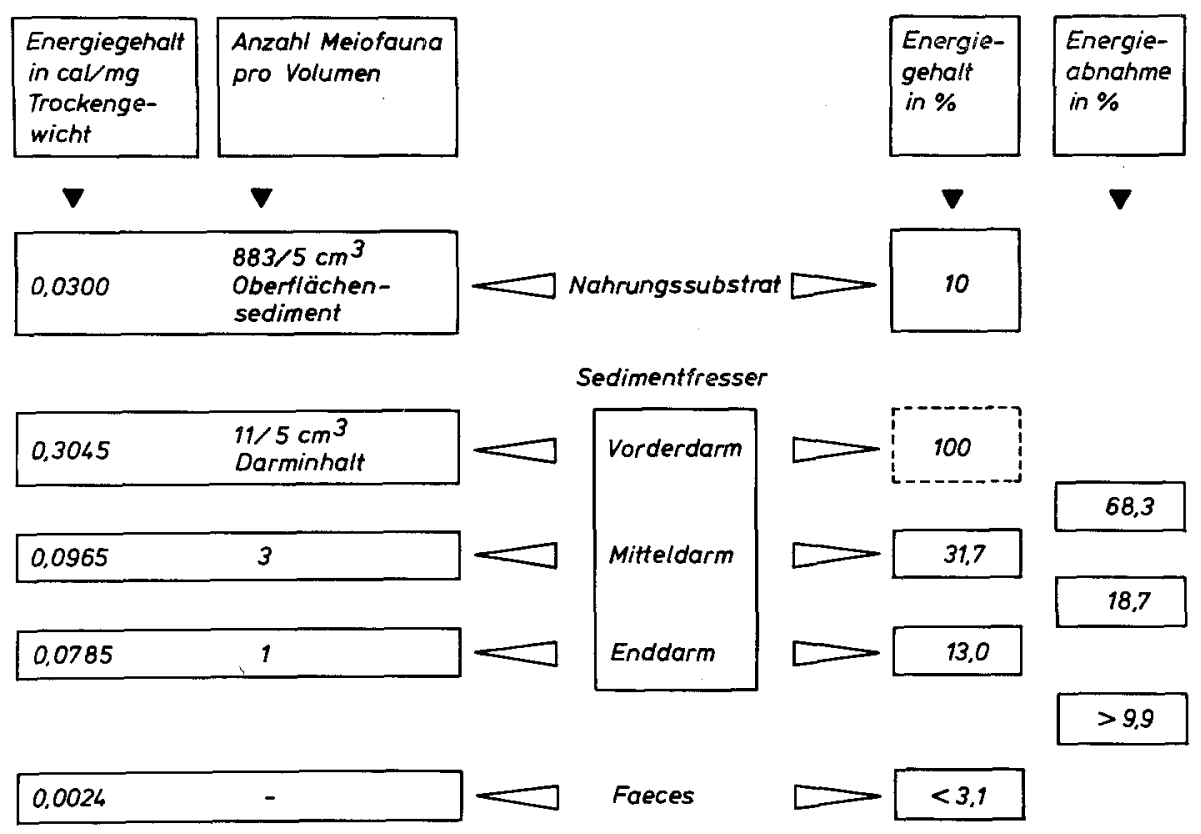

Abb. 1: Ausnutzung der durchschnittlich aufgenommenen Energie durch Sipunculus nudus

In den folgenden Ausführungen soll nun einmal versucht werden, mit Hilfe der vorliegenden Ergebnisse aus dem Tidengebiet von Arcachon für den Sedimentfresser S. nudus (ein Individuum mittleren Gewichts, ca. $26 \mathrm{~g}$ ) eine Bilanzierung der energetischen Vorgänge im Sedimentkörper vorzunehmen. In diese vorläufige Abschätzung wird eine etwaige Ortsbewegung der Tiere nicht miteinbezogen; hierfür ist allerdings auf Grund des regelmäßigen reichen Nahrungseintrags auch keine Notwendigkeit gegeben. Da für die Darmdurchlaufzeit durchschnittlich 19 Stunden gemessen wurde, ergibt sich aus dem Darmvolumen und der Verweilzeit des aufgenommenen Nahrungs- 
substrats in den Tieren ein Tagesdurchsatz von rund $23 \mathrm{~cm}^{3}$ Sediment; das bedeutet ein Mindest-Jahres-"turnover" von rund $8400 \mathrm{~cm}^{3}$ durch einen Sipunculiden unter den vorliegenden Bedingungen. Umgerechnet in Trockengewicht ergibt sich ein jährliches "turnover" von 3,1 kg Trockengewicht des Sediments pro Tier. Hierzu gibt Nichols (1974) für den Polychaeten Pectinaria californiensis einen jährlichen Umsatz von $8,6 \mathrm{~kg}$ an, wobei zu bedenken ist, daß dieser Polychaet kleiner ist, keinen gewundenen Darm und daher vermutlich eine vergleichsweise kürzere Darmdurchlaufzeit hat. Da für $1 \mathrm{~cm}^{3}$ Sediment ein durchschnittlicher Kaloriengehalt von 33 cal errechnet wurde, entspricht die pro Jahr aufgenommene Sedimentmenge einem Energiewert von $277 \mathrm{kcal}$. Das Nahrungssubstrat wird durch den Darmtrakt hindurchgeschleust und der Energiewert dem Sediment fast vollständig entzogen, da in den Faeces organische Substanz praktisch nicht mehr vorhanden ist. Diese intensive Nahrungsausnutzung ist verständlich aus der tidenbedingten Abhängigkeit der Freßperioden der Tiere. Vermutlich wird in der Zeit des Trockenfallens des Sediments die aufgenommene Nahrung durch diese Sedimentfresser intensiv und vollständig absorbiert, so daß bei Aufsammlung der Tiere z. Z. der Ebbe im Enddarm nur noch relativ wenig Energiegehalt vorhanden ist. Mit der Wasserbedeckung ist dann auch wieder ein reicher Eintrag an energiereichem Detritus - auch aus anderen Biotopen - gegeben; ein Eintrag, der durch die hohen Produktionsraten von Mikroorganismen und durch höhere Organismen produzierten bzw. sedimentierten fecal pellets verstärkt wird.

Um einen Ansatzpunkt für die Zusammensetzung der Nahrung der Sipunculiden zu finden, wurden Vorderdarm-Untersuchungen durchgeführt. Die Zusammensetzung der aufgenommenen Nahrung im Vorderdarm bestand zu etwa $55 \%$ aus fecal pellets und $45 \%$ Detritus sowie Mikroorganismen. Der Anteil der zahlenmäßig erfaßten Meiofauna betrug nur 0,03\%. Von der in der Oberfläche von $1 \mathrm{~m}^{2}(0,5 \mathrm{~cm}$ Sedimenttiefe) lebenden Meiofauna wird von den unter dieser Fläche gefundenen durchschnittlich 5 Sipunculiden im Jahr nur 5,5\% weggef ressen, d. h. also, daß die Meiofauna zwar nicht ohne Bedeutung ist, wohl aber an der Gesamtnahrung zu weitaus weniger als $1 \%$ beteiligt ist. McIntyre (1971) hat nach seinen Untersuchungen die These vertreten, daß die Meiofauna das Endglied einer interstitiellen Nahrungskette "gelöste organische Substanz - Bakterien - Meiofauna" ist. In dem von ihm untersuchten Biotop herrscht ein sandiges Sediment vor; hier besteht für die Meiofauna nicht die Gefahr des Gefressenwerdens, da Makrofauna in diesem Gebiet fehlt. Die vorliegenden Untersuchungen haben gezeigt, daß selbst in einem Lebensraum, in dem Makrofauna vorhanden ist und damit ein Prädator gegeben ist, die Meiofauna nur zu $0,03 \%$ in der aufgenommenen Nahrung wiedergefunden wird.

Die in dieser Arbeit durchgeführten Untersuchungen zur Nahrung von Sedimentfressern haben zweierlei Schwierigkeiten erkennen lassen: (1.) Eine quantitative Differenzierung der einzelnen Nahrungskomponenten des Substrats war nur teilweise möglich. Es muß eine Wertung durchzuführen sein, wobei besonders auch auf die Beziehungen dieser Komponenten untereinander zu achten ist, wie z. B. bei den fecal pellets und den aufsitzenden Mikroorganismen. Erste Schritte hierzu wurden in dieser Arbeit unternommen. (2.) Es ist notwendig, die mit dem Kalorimeter objektiv gemessenen Energiewerte der entsprechenden vom Tier verwertbaren Nahrung zuzuordnen. Hier$\mathrm{zu}$ sind Fütterungsexperimente notwendig, um eine weiterführende Aussage zu errei- 
chen. Erst wenn durch weitere Untersuchungen eine den obigen Punkten entsprechende Unterscheidung möglich ist, kann die Nahrung von Sedimentfressern quantitativ und qualitativ sicher bestimmt werden.

Danksagungen. Herrn Dr. H. Thiel danke ich für die Themenstellung, die ständige Bereitschaft zur kritischen Diskussion der Ergebnisse sowie für die Bereitstellung von Mitteln zur Beschaffung des Versuchsmaterials in Arcachon/Frankreich. Dr. C. Cazaux, Direktor des Institut de Biologie Marine der Universität Bordeaux in Arcachon, sowie seine Mitarbeiter unterstützten in dankenswerter Weise meine dortigen Untersuchungen. Bei der Gewinnung von Freilandmaterial half mir Frau K. Schrey. Weiterhin danke ich den Teilnehmern eines Arbeitstreffens der "Baltic Marine Biologists" in Askö (Schweden) im September 1974 - insbesondere Dr. R. Elmgren - für die Bereitstellung des hierbei gewonnenen, sortierten Lebendmaterials. Bei Dr. G.-A. Paffenhöfer bedanke ich mich für die Hilfestellung bei der Einarbeitung in die Kalorimetrie.

\section{ZITIERTE LITERATUR}

Arakawa, K. Y., 1970. Scatological studies of the Bivalvia (Mollusca). Adv. mar. Biol. 8, $307-436$.

Boje, R., 1965. Die Bedeutung von Nahrungsfaktoren für das Wachstum von Mytilus edulis L. in der Kieler Förde und im Nord-Ostsee-Kanal. Kieler Meeresforsch. 21, 81-100.

Boysen Jensen, P., 1919. Valuation of the Limfjord 1. Rep. Dan. biol. Stn 26, 1-24.

Brawn, V. M., Peer, D. L. \& Bentley, R. J., 1968. Caloric content of the standing crop of benthic and epibenthic invertebrates of St. Margarets Bay, Nova Scotia. J. Fish. Res. Bd Can. 25, 1803-1811.

Bröckel, K. von, 1973. Eine Methode zur Bestimmung des Kaloriengehaltes von Seston. Kieler Meeresforsch. 24, 34-49.

Coull, B. C., 1969. Shallow water meiobenthos of the Bermuda Platform. Oecologia 4, 325-357.

Crisp, R. J., 1971. Energy flow measurements. In: Methods of the study of marine benthos. Ed. by N. A. Holme \& A. D. McIntyre. Blackwell, Oxford, 197-280 (IPB Handbook Nr. 16).

Cummins, K. W. \& Wuycheck, J. C., 1971. Caloric equivalents for investigations in ecological energetics. Mitt. int. Verein. theor. angew. Limnol. 18, 1-8.

Elmgren, R., 1973. Recommendations for quantitative meiofauna work in the Baltic. In: Circular, Meiofauna Working Group, Baltic Marine Biologists, 11, 1-4.

- \& Ganning, B., 1974. Ecological studies of two shallow brackish water ecosystems. Contrib. Askö Lab. 6, 1-56.

Fenchel, T., 1969. The ecology of marine meiobenthos - IV. Structure and function of the benthic ecosystem, its chemical and physical factors and the microfauna communities with special reference to ciliated protozoa. Ophelia $6,1-182$.

Foster-Smith, R., 1975. The effect of concentration of suspension on the filtration rate and pseudofecal production for Mytilus edulis L., Cerastoderma edule L. and Venerupis pullastra (Montagu). J. exp. mar. Biol. Ecol. 17, 1-22.

Frankenberg, D., Coles, S. L. \& Johannes, R. E., 1967. The potential trophic significance of Callianassa major fecal pellets. Limnol. Oceanogr. 12, 113-120.

- \& Smith, K. L., 1967. Coprophagy in marine animals. Limnol. Oceanogr. 12, 443-450.

Gauld, D. T., 1957. A peritrophic membrane in calanoid copepods. Nature, Lond. 179, 325-326.

Gentry \& Wiegert, 1969. Assembly and operating instructions for the Phillipson oxygen microbomb calorimeter. Gentry \& Wiegert Instr. Inc., Aiken, 4 pp.

Gerlach, S. A., 1971. On the importance of marine meiofauna for benthos communities. Oecologia 6, 176-190.

Goerke, H., 1971a. Nahrungsaufnahme, Nahrungsausnutzung und Wachstum von Nereis virens (Polychaeta, Nereidae). Veröff. Inst. Meeresforsch. Bremerh. 13, 51-78. 
- 1971b. Die Ennährungsweise der Nereis-Arten (Polychaeta, Nereidae) der deutschen Küsten. Veröff. Inst. Meeresforsch. Bremerh. 13, 1-50.

Gray, J. S., 1966. Selection of sands by Protodrilus symbioticus Giard. Veröff. Inst. Meeresforsch. Bremerh. (Sonderbd) 2, 105-116.

- 1967. Substrate selection by the archiannelid Protodrilus rubropharyngeus. Helgoländer wiss. Meeresunters. 15, 255-269.

Guille, A. \& Soyer, J., 1969. La fauna benthique des substrats meubles de Banyuls-sur-mer. Prémiers données qualitatives et quantitatives. Vie Milieu (B) 19, 323-359.

Hartwig, E., 1973. Die Ciliaten des Gezeiten-Sandstrandes der Nordseeinsel Sylt. II. Ơkologie. Mikrofauna Meeresboden 21, 1-171.

Hughes, R. N., 1970. An energy budget for a tidal-flat population of the bivalve Scrobicularia plana. J. Anim. Ecol. 39, 357-379.

Hylleberg, J., 1975. Selective feeding by Abarenicola pacifica with notes on Abarenicola vagabunda and a concept of gardening in lugworms. Ophelia 14, 113-137.

Jørgensen, C. B., 1962. The food of filter feeding organisms. Rapp. P.-V. Réun. Cons. perm. int. Explor. Mer 153, 39-47.

- 1966. Biology of suspension feeding. Pergamon Press, New York, $357 \mathrm{pp}$.

Johannes, R. E. \& Satomi, M., 1966. Composition and nutritive value of fecal pellets of a marine crustacean. Limnol. Oceanogr. 11, 191-197.

Jones, N. S., 1956. The fauna and biomass of a muddy sand deposit off Port Erin, I.O.M. J. Anim. Ecol. 25, 217-252.

Kersting, K., 1972. A nitrogen correction for caloric values. Limnol. Oceanogr. 17, 643-644.

Krüger, F., 1971. Bau und Leben des Wattwurmes Arenicola marina. Helgoländer wiss. Meeresunters. 22, 149-200.

Krumbein, W. E., 1971. Sediment microbiology and grain-size distribution as related to tidal movement, during the first mission of the West German Underwater Laboratory "Helgoland". Mar. Biol. 10, 101-112.

Lindeman, R. L., 1942. The trophic-dynamic aspect of ecology. Ecology 23, 399-418.

MacGinitie, G. E., 1932. The role of bacteria as food for bottom animals. Science, N. Y. 76, 490.

McIntyre, A. D., 1964. Meiobenthos of sublittoral muds. J. mar. biol. Ass. U.K. 44, 665-674.

- 1971. Marine zoobenthos in the light of recent research. Proc. Joint Oceanogr. Assembly, Tokyo 1970, 139-141.

Meadows, P. S. \& Anderson, J. G., 1966. Micro-organisms attached to marine and freshwater sand grains. Nature, Lond. 212, 1059-1060.

Moore, H. B., 1931a. The specific identification of fecal pellets. J. mar. biol. Ass. U.K. 17, 359-365.

- 1931b. The form of fecal pellets and specific identification. Nature, Lond. 127, 818.

Moshiri, G. G., 1968. Energetics of the predaceous zooplankter Leptodora kindtii (Focke) and selected prey species. Ph. D., Diss. Univ. of Pittsburgh, 148 pp. (Unpubl.).

Moshiri, G. A. \& Cummins, K. W., 1969. Calorific values of Leptodora kindtii Focke (Crustacea Cladocera) and selected food organisms. Arch. Hydrobiol. 66, 91-99.

Muus, B. J., 1967. The fauna of Danish estuaries and lagoons: Distribution and ecology of dominating species in the shallow reaches of the mesohaline zone. Meddr. Danm. Fisk, $-o g$ Havunders. 5, 3-316.

Newell, R., 1965. The role of detritus in the nutrition of two marine deposit feeders, the prosobranch Hydrobia ulvae and the bivalve Macoma baltica. Proc. zool. Soc. Lond. 144, $25-45$.

- \& Bayne, B. L., 1973. A review on temperature and metabolic acclimation in intertidal marine invertebrates. Neth. J. Sea Res. 7, 421-433.

Nichols, F. H., 1974. Sediment turnover by a deposit-feeding polychaete. Limnol. Oceanogr. 19, 945-950.

Odum, E. P., 1959. Fundamentals of ecology. Philadelphia, Saunders, 546 pp.

Paine, R. T., 1964. Ash and caloric determinations of sponge and opisthobranch tissues. Eco$\operatorname{logy} 45,384-387$. 
- 1966. Endothermy in bomb calorimetry. Limnol. Oceanogr. 11, 126-129.

Pamatmat, M. M., 1968. Ecology and metabolism of a benthic community on an intertidal sand flat. Int. Revue ges. Hydrobiol. 53, 211-298.

Phillipson, J., 1964. A miniature bomb calorimeter for small biological samples. Oikos 15, $130-139$.

Prus, T., 1970. Calorific value of animals as an element of bioenergetical investigations. Polskie Arch. Hydrobiol. 17, 183-199.

Rachor, E., 1975. Quantitative Untersuchungen über das Meiobenthos der nordatlantischen Tiefsee. Meteor Forsch.Ergebn. (D) 21, 1-10.

Richman, S., 1971. Calorimetry. In: A manual on the methods for the asessment of secondary productivity in fresh waters. Ed. by W. T. Edmondson \& G. G. Winberg. Blackwell, Oxford 146-149 (IPB Handbook Nr. 17).

Romijn, C., 1946. Verbleibzeit und Durchgangszeit der Nahrung bei Vertebraten und Invertebraten. Tabul. biol. 21 (1), 186-197.

Scheibel, W. \& Noodt, W., 1975. Population densities and characteristics of meiobenthos in different substrates in the Kiel Bay. Merentutkimuslait. Julk. 239, 173-178.

Steele, J. H., 1970. Marine Food Chains. University of California Press, Berkely, 552 pp.

Stripp, K., 1969. Jahreszeitliche Fluktuationen von Makrofauna und Meiofauna in der Helgoländer Bucht. Veröff. Inst. Meeresforsch. Bremerh. 12, 65-94.

Tétry, A., 1959. Les sipunculiens. In: Traité de Zoologie. Ed. by P. P. Grassé. Masson, Paris, 5, $785-854$.

Theede, H., 1963. Experimentelle Untersuchungen über die Filtrationsleistung der Miesmuschel Mytilus edulis L. Kieler Meeresforsch. 19, 20-41.

Thiel, H., 1966. Quantitative Untersuchungen über die Meiofauna des Tiefseebodens (vorläufiges Ergebnis der "Meteor"-Expedition in den Indischen Ozean). Veröff. Inst. Meeresforsch. Bremerh. (Sonderbd) 2, 131-147.

Tietjen, J. H., 1969. The ecology of shallow water meiofauna in two New England estuaries. Oecologia 2, 251-291.

Vinogradov, M. E., 1970. Vertical distribution of the oceanic zooplankton. Israel Program for Scient. Transl. Jerusalem, $339 \mathrm{pp}$.

Walter, M. D., 1973. Freßverhalten und Darminhaltsuntersuchungen bei Sipunculiden. Helgoländer wiss. Meeresunters. 25, 486-494.

Whitlatch, R. B., 1974. Food-resource partitioning in the deposit-feeding polychaete Pectinaria gouldii. Biol. Bull. mar. biol. Lab., Woods Hole 147, 227-235.

Wieser, W., 1960. Benthic studies in Buzzards Bay. II. The meiofauna. Limnol. Oceanogr. 5, 121-137.

Wigley, R. L. \& McIntyre, A. D., 1964. Some quantitative comparisons on offshore meiobenthos and macrobenthos south of Martha's vineyard. Limnol. Oceanogr. 9, 485-493.

Yonge, C. M., 1928. Feeding mechanisms in the invertebrates. Biol. Rev. 3, 21-76. 